\title{
Branching and converging pathways in fungal natural product biosynthesis
}

\author{
Xingxing Wei ${ }^{1} \mathbb{B}$, Wei-Guang Wang ${ }^{2}$ (D) and Yudai Matsuda ${ }^{1 *}$ (])
}

\begin{abstract}
In nature, organic molecules with great structural diversity and complexity are synthesized by utilizing a relatively small number of starting materials. A synthetic strategy adopted by nature is pathway branching, in which a common biosynthetic intermediate is transformed into different end products. A natural product can also be synthesized by the fusion of two or more precursors generated from separate metabolic pathways. This review article summarizes several representative branching and converging pathways in fungal natural product biosynthesis to illuminate how fungi are capable of synthesizing a diverse array of natural products.
\end{abstract}

Keywords: Natural products, Biosynthesis, Branching and converging pathways

\section{Introduction}

Structural diversity is a characteristic feature of naturally occurring organic compounds (natural products). Natural products possess a wide range of biological activities that can be attributed to their diverse and complicated molecular architectures. In nature, a great array of natural products are synthesized from a relatively small number of starting materials derived from primary metabolism. One reason behind the structural diversity of natural products is the presence of a significant number of core synth(et)ases, which are involved in the backbone synthesis of natural products. Core synth(et) ases include polyketide synthases (PKSs), nonribosomal peptide synthetases (NRPSs), and terpene cyclases and are often responsible for the first committed step of a natural product biosynthesis, providing branching points between primary and secondary metabolic pathways. For example, PKSs accept limited starter and extender units, as represented by acetyl-coenzyme $\mathrm{A}(\mathrm{CoA})$ and malonyl$\mathrm{CoA}$, and perform repeated condensation of $\mathrm{C}_{2}$ units to generate polyketide products with diverse chain lengths,

*Correspondence: ymatsuda@cityu.edu.hk

1 Department of Chemistry, City University of Hong Kong, Tat Chee Avenue, Kowloon, Hong Kong SAR, China

Full list of author information is available at the end of the article oxidation levels, or cyclization patterns [1, 2]. Although polyketide biosynthesis resembles that of fatty acids, an incomparable number of molecules can be produced by PKSs [3]. Likewise, terpene cyclases can cyclize achiral and linear substrates, such as polyprenyl pyrophosphates and (oxido)squalene, in a diverse manner, generating great structural diversity in terpene natural products [4].

In addition to structural diversification by core synth(et)ases, nature also uses other synthetic strategies to afford a variety of natural products [5]. Pathway branching is one such example, in which a molecule is synthesized as a common biosynthetic precursor and then undergoes distinct tailoring reactions to generate several different natural products (Fig. 1A). In another biosynthetic process, two or more molecules synthesized in separate pathways are combined together to provide a single natural product (Fig. 1B). In other words, convergent biosynthesis is nature's alternate approach to expand natural product diversity. Recent advances in genome sequencing technology and the development of molecular biological tools have allowed the elucidation of biosynthetic pathways and the synthesis of many natural products, including those synthesized in branching and converging pathways. In this review article, we summarize representative examples of branching and converging pathways in fungal natural product biosynthesis, with

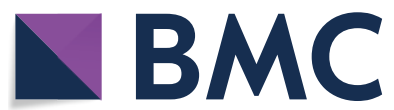

(c) The Author(s) 2022. Open Access This article is licensed under a Creative Commons Attribution 4.0 International License, which permits use, sharing, adaptation, distribution and reproduction in any medium or format, as long as you give appropriate credit to the original author(s) and the source, provide a link to the Creative Commons licence, and indicate if changes were made. The images or other third party material in this article are included in the article's Creative Commons licence, unless indicated otherwise in a credit line to the material. If material is not included in the article's Creative Commons licence and your intended use is not permitted by statutory regulation or exceeds the permitted use, you will need to obtain permission directly from the copyright holder. To view a copy of this licence, visit http://creativecommons.org/licenses/by/4.0/. The Creative Commons Public Domain Dedication waiver (http://creativeco mmons.org/publicdomain/zero/1.0/) applies to the data made available in this article, unless otherwise stated in a credit line to the data. 


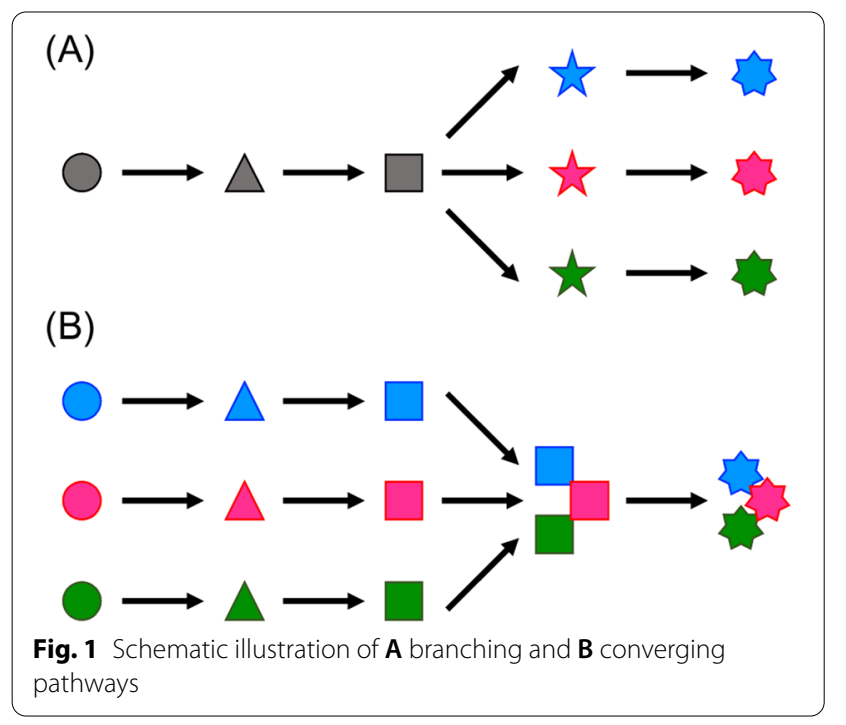

the aim to highlight nature's sophisticated strategies for synthesizing diverse molecules.

\section{Branching pathways}

As mentioned above, core synth(et)ases utilize substrates also used by the enzymes involved in primary metabolism but synthesize diverse molecules, thus greatly contributing to pathway divergence in natural product biosynthesis. As the functions and diversity of core synth(et) ases are well summarized elsewhere [1, 2, 4], this review focuses on the biosynthetic processes in which pathway branching occurs at the mid- or late-biosynthesis stage, especially those in which a single molecule serves as a common precursor of more than two different pathways.

\section{Fungal xanthones}

Xanthone is a tricyclic organic molecule, and xanthone derivatives are a class of natural products that exhibit a wide range of biological activities such as anti-bacterial activities and cytotoxicity [6, 7]. Fungi are prolific producers of natural products with a xanthone (including di- and tetrahydroxanthone [THX]) scaffold (Fig. 2). In recent years, biosynthetic gene clusters of several fungal xanthones have been identified and characterized, revealing how fungi produce diverse xanthone compounds [816]. Although the xanthone skeleton can be synthesized through several different pathways in nature, all fungal xanthones are considered to be derived from the anthraquinone chrysophanol (1), which is generated by seven enzymes from one acetyl-CoA molecule and seven malonyl-CoA molecules [12].

Blennolides A-C (2-4) are representative fungal THXs and the precursors of many THX dimers [17], such as secalonic acids and neosartorin [18-20]. In the biosynthesis of neosartorin, chrysophanol (1) is transformed into monodictyphenone (5) and isomonodictyphenone (6), providing a branching point (Fig. 3A) [12]. Previously, it was thought that NsrF serves as a Baeyer-Villiger monooxygenase to insert an oxygen atom at two different positions in $\mathbf{1}[12,15]$. However, the recent in-depth characterization of GedF, an NsrF homologue in geodin biosynthesis, indicated that chrysophanol is not a direct NsrF substrate [21]. It is currently proposed that $\mathbf{1}$ is first reduced to chrysophanol hydroquinone (7) by the shortchain dehydrogenase/reductase (SDR) NsrR, which is also required for chrysophanol formation. NsrF then accepts 7 to deprotonate from the $\mathrm{C}-10$ position, followed by single electron transfer (SET) from the carbanion to molecular oxygen to generate the peroxy anion 8 . The peroxy anion 8 subsequently attacks either the C-4a or $\mathrm{C}-10 \mathrm{a}$ position, followed by bond migration to yield 5 or $\mathbf{6}$, respectively (Fig. 3B). Interestingly, $\mathrm{AacuH}$, the NsrF homologue engaged in secalonic acid biosynthesis, selectively generates 5 [16], indicating that this enzyme controls Michael addition by the peroxy anion.

Monodictyphenone (5) and isomonodictyphenone (6) undergo methyl-esterification to afford 2,2',6'-trihydroxy-4-methyl-6-methoxyacyldiphenylmethanone (9; hereby termed isomoniliphenone) and moniliphenone (10), respectively, both of which are key blennolide precursors (Fig. 3A). Compound 9 can be converted into blennolide A (2), blennolide B (3), and (-)-blennolide

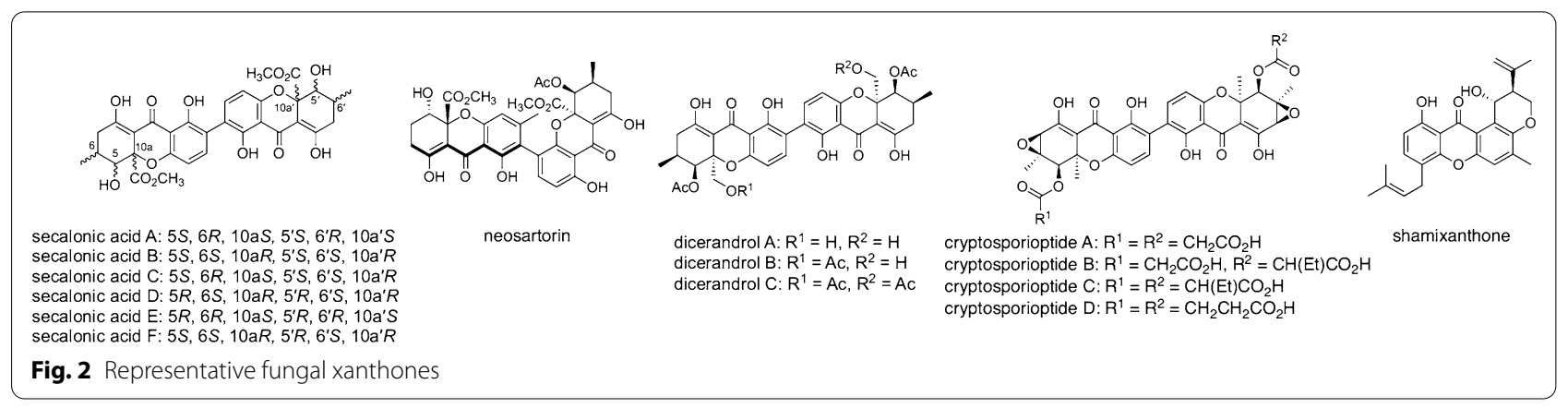




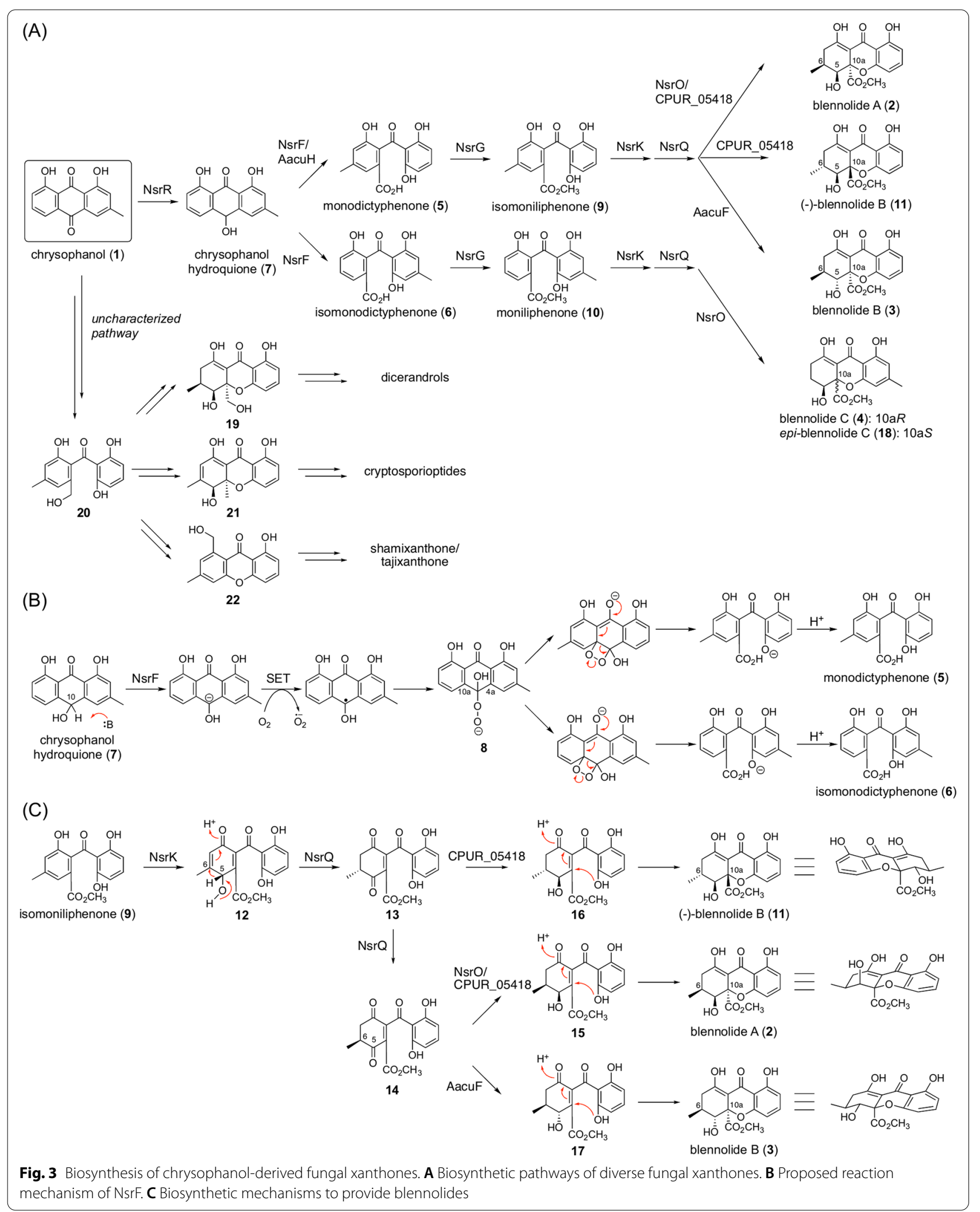


B (11) (Fig. 3C) [15]. In the neosartorin pathway, 9 is almost exclusively transformed to 2, in which three enzymes, the flavin-dependent monooxygenase (FMO) NsrK, the isomerase NsrQ, and the SDR NsrO, collaboratively synthesize the THX scaffold [22]. In this biosynthetic process, NsrK initially performs hydroxylation at the $\mathrm{C}-5$ position, and the resultant hydroxycyclohexadienone 12 undergoes NsrQ-catalyzed isomerization to provide the cyclohexanedione intermediate 13. NsrQ subsequently inverts the stereochemistry at the C-6 position to give 14. NsrO then reduces the C-5 carbonyl of 14 to the (5S)-hydroxy group to yield 15 , followed by spontaneous heterocyclization to yield 2 . This cyclization appears to occur in a stereoselective manner to avoid the 1,3-axial-pseudoaxial interaction between the C-6 methyl group and the C-10a methyl ester. Intriguingly, CPUR_05418, a NsrO homologue in Claviceps purpurea, accepts the first isomerized product of NsrQ, 13, and serves as the C-5S reductase to generate $\mathbf{1 1}$ with a $(5 S, 6 R, 10 \mathrm{a} S)$ configuration via 16. Furthermore, the Aspergillus aculeatus secalonic acid pathway adopts two SDRs with distinct stereoselectivity [14]. One SDR, AacuD, is homologous to NsrO and responsible for blennolide A formation, whereas the other SDR AacuF conducts the $C-5 R$ reduction, leading to the production of 3 possessing the $(5 R, 6 S, 10 \mathrm{a} R)$ configuration via 17 [16]. In addition, 10 undergoes similar reactions catalyzed by NsrK, NsrQ, and NsrO to yield blennolide C (4) and its C-10a epimer epi-blennolide C (18) [15]; cyclization occurs in a nonselective manner, probably due to lack of the C-6 methyl group.

Chrysophanol (1) appears to be the precursor of many other fungal xanthones whose biosynthetic pathways have not been fully elucidated. On the basis of the dicerandrol structure [23, 24], their biosynthesis should involve a precursor that is analogous to blennolide A (2) but contains a hydroxymethyl group instead of a methyl ester, 19 (Fig. 3A), which is derived from a monodictyphenone analogue 20 with a hydroxymethyl group. Compound 20 could also be utilized as a common biosynthetic intermediate for other fungal xanthones, such as cryptosporioptide (via 21) [14] and tajixanthone/shamixanthone (via 22) [8], although the mechanism to provide the hydroxymethyl group has yet to be elucidated.

\section{Ergot alkaloids}

Ergot alkaloids are a diverse group of fungal indole alkaloids with pharmaceutical and agricultural value $[25$, 26]. They are synthesized by filamentous fungi of several different genera and provide another example in which pathway branching significantly contributes to structural diversification. All ergot alkaloids are believed to be biosynthesized from chanoclavine-I aldehyde (23) as a common precursor (Fig. 4A), which is generated by five dedicated enzymes using L-tryptophan and dimethylallyl pyrophosphate (DMAPP) as starting materials.

Chanoclavine-I aldehyde (23) is converted into lysergic acid (24) in several fungi, such as Epichloë lolii and Claviceps purpurea. In this transformation, 23 is accepted by EasA (Nl_EasA or Cp_EasA) to undergo double-bond isomerization, followed by spontaneous cyclization [27, 28]. The resultant iminium cation $\mathbf{2 5}$ is then reduced by the SDR EasG to provide agroclavine (26) [29], which is further converted to 24 (Fig. 4A). Meanwhile, in Aspergillus or Penicillium species, the ergot alkaloid pathways use an EasA homologue (Af_EasA or Aj_EasA) with reductase activity to provide 27 (Fig. 4A) [27, 28, 30, 31]. The catalytic tyrosine residue in the reductase version of EasA is substituted with phenylalanine in the isomerasetype EasA [28], which cannot perform the reduction reaction, thus causing functional differences in the EasA homologues. In Aspergillus fumigatus, 27 is predominantly converted to festuclavine (28) by EasG (Af_EasG), whereas a considerable amount of pyroclavine (29), the C-8 epimer of $\mathbf{2 8}$, is also produced by the homologous enzyme Pc_EasG in Penicillium commune [32]. Compounds 28 and 29 undergo further tailoring reactions to give $(8 S, 9 S)$-fumigaclavine $\mathrm{C}$ (30) in A. fumigatus and $(8 R, 9 S)$-fumigaclavine A (31) in P. commune, respectively, as the end products. Intriguingly, in A. japonicus, another enzyme, EasH ( $\left.\mathrm{Aj}_{-} E a s H\right)$, which is an $\alpha$-ketoglutarate $(\alpha \mathrm{KG})$-dependent dioxygenase, acts before the EasG reduction to catalyze structural rearrangement to install the cyclopropane moiety to yield $\mathbf{3 2}$, eventually leading to the production of cycloclavine (33) [31].

Lysergic acid (24) undergoes further modification by several NRPSs to yield ergopeptines and lysergic acid amides (Fig. 4B). In C. purpurea, 24 is activated by and loaded onto a single-module NRPS, LPSB, with adenylation (A)-thiolation (T)-condensation (C) domain organization [33-35]. The activated 24 is then transferred to the assembly line of LPSA1 or LPSA2, two other NRPSs homologous to each other [35]. After the incorporation of three amino acids, the elongated peptide chain is released by the terminal condensation-like $\left(\mathrm{C}_{\mathrm{T}}\right)$ domain to furnish the diketopiperazine structure. The resultant ergopeptams are then transformed into ergopeptines, namely ergotamine (34) and ergocryptine (35), by the $\alpha$ KG-dependent dioxygenase Cp_EasH [36]. LPSA1 and LPSA2 have the same domain architecture but utilize different combinations of amino acids. It has been proposed that the three LPSA1 A domains activate $\mathrm{L}$-alanine, $\mathrm{L}$-phenylalanine, and L-proline, and that those of LPSA2 recognize L-valine, L-leucine, and L-proline [37]. Furthermore, LPSB-loaded $\mathbf{2 4}$ can be utilized by another single module NRPS with 


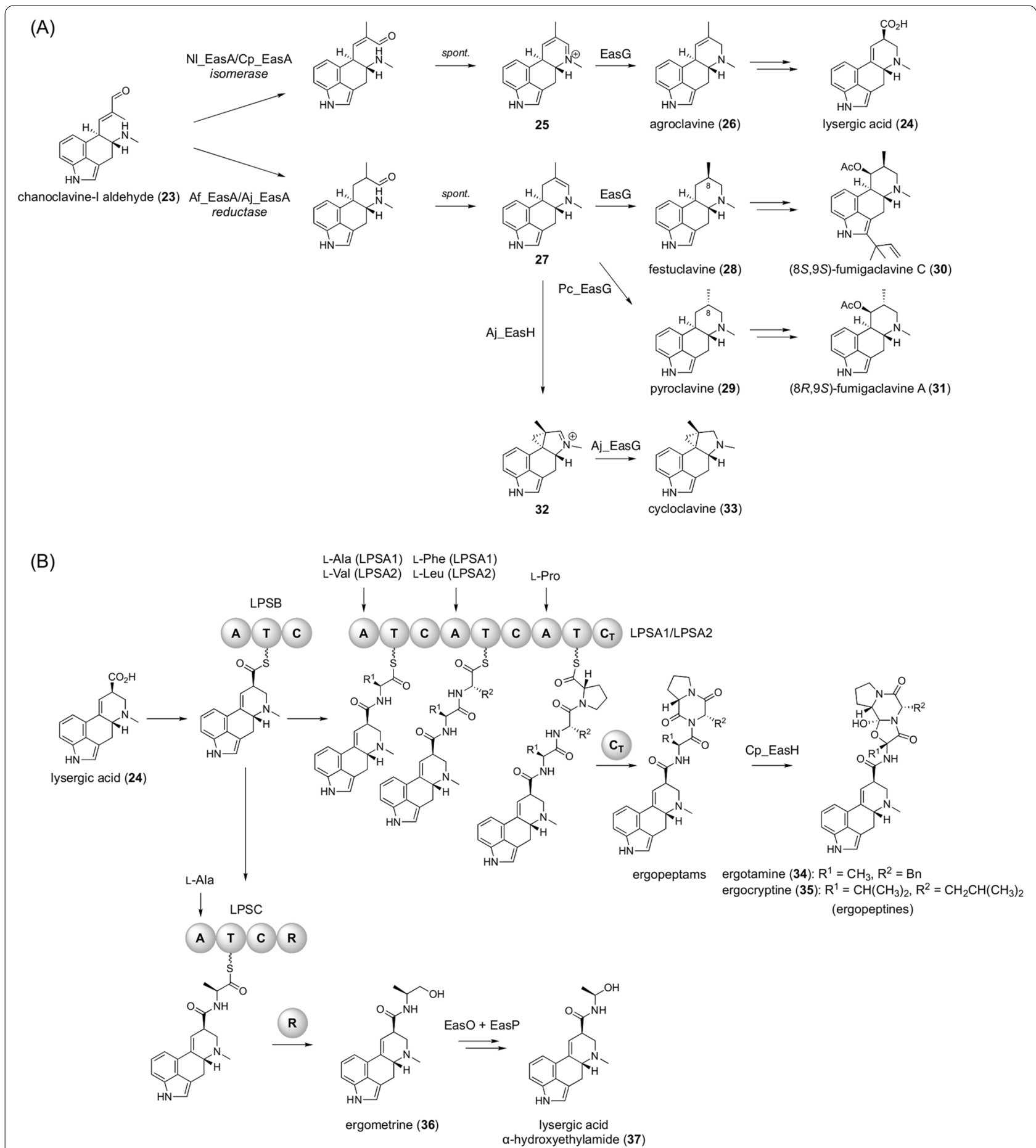

Fig. 4 Biosynthesis of ergot alkaloids. A Branched biosynthesis of ergot alkaloids in filamentous fungi. B Biosynthesis of ergopeptines and lysergic acid amides in Claviceps

A-T-C-reductase (R) domain organization, LPSC, thus incorporating $\mathrm{L}$-alanine and forming ergometrine (36) by reductive release of the peptide chain [34]. In some fungi, such as Claviceps paspali, 36 can be further transformed into lysergic acid $\alpha$-hydroxyethylamide (37; LAH), which is thought to be produced by the FMO EasO and $\alpha / \beta$ hydrolase-fold enzyme EasP [38]. 


\section{Trichothecenes}

Trichothecenes are a large group of sesquiterpenoid mycotoxins produced by a variety of fungi of different genera and represented by $\mathrm{T}-2$ toxin (38) and satratoxin H (39) (Fig. 5) [39, 40]. The trichothecene core structure features an epoxide ring at the $\mathrm{C}-12 / \mathrm{C}-13$ positions, which is crucial for their biological activities. The first committed biosynthesis step of all trichothecenes is the cyclization of farnesyl pyrophosphate (FPP) into the sesquiterpene hydrocarbon trichodiene (40), which is catalyzed by the terpene cyclase Tri5 (Fig. 5A) [41, 42]. The sesquiterpene $\mathbf{4 0}$ then undergoes multiple oxidations catalyzed by the cytochrome P450 monooxygenase Tri4. In Fusarium fungi, Tri4 is responsible for four successive oxidative reactions to afford isotrichotriol (41), which spontaneously cyclizes to isotrichodermol (42) [43]. Contrarily, Tri4 in other fungi only performs three rounds of oxidations to yield isotrichodiol (43), which is nonenzymatically transformed into 12,13-epoxytrichothec-9-ene (44; EPT) [43, 44]. Thus, functional differences in Tri4 provide the first branching point in fungal trichothecene biosynthesis.

Isotrichodermol (42) in Fusarium is subsequently converted to calonectrin (45) by three enzymes, the acetyltransferase Tri101 [45], the P450 Tri11 [46], and the acetyltransferase Tri3 [47, 48] (Fig. 5A). In Fusarium sporotrichioides, a known producer of the $\mathrm{T}-2$ toxin (38), 45 is converted to 3,4,15-triacetoxyscirpenol (46) by P450 Tri13 [49] and the acetyltransferase Tri7 [50] (Fig. 5B). Then, $\mathbf{4 6}$ is hydroxylated by P450 Tri1 (FsTri1) to give 3-acetylneosolaniol (47) [51]. Finally, the acyltransferase Tri16 [52], which installs the isovaleryl sidechain that possibly utilizes isovaleryl-CoA, and the esterase Tri8 complete the biosynthesis to afford the $\mathbf{3 8}$ [53]. Meanwhile, another Fusarium species, F. graminearum, also employs $\mathbf{4 5}$ as a key biosynthetic intermediate for trichothecenes but produces different molecules than F. sporotrichioides (Fig. 5B). F. graminearum is further classified into two major types based on their metabolic profiles: the deoxynivalenol (DON) and nivalenol (NIV) chemotypes [54]. In both chemotypes, 45 first undergoes multiple oxidations to be converted to 3,15-diacetyldeoxynivalenol (48). This transformation is catalyzed by $\mathrm{P} 450$ Tri1 (FgTri1) [55], which has a function distinct from its corresponding enzyme (FsTri1) in the T-2 toxin pathway. The difference between the DON and NIV chemotypes is attributed to P450 Tri13 inactivation in the DON chemotype $[49,56]$. In the NIV chemotype, Tri13 hydroxylates 48 to yield 3,15-diacetylnivalenol (49), which is further transformed into nivalenol (50). Meanwhile, in the DON chemotype, 48 undergoes deacetylation to yield deoxynivalenol (51) via 3-acetyldeoxynivalenol (52) or 15-acetyldeoxynivalenol (53).
In fungal species other than Fusarium, EPT (44), an isotrichodermol deoxy analogue, is used as a common precursor of trichothecenes, which often have side chain(s) derived from the polyketide pathway (Fig. 5C). In Trichoderma arundinaceum, which produces harzianum A (54), 44 is hydroxylated by P450 Tri11 (TaTri11) to give trichodermol (55) [57], which is further transformed into 54. This acylation reaction requires at least four enzymes, namely PKS Tri17, P450 Tri23, and two acyltransferases, Tri3 and Tri18 [58]. Although the detailed acylation mechanism has yet to be clarified, it has been proposed that Tri17 synthesizes octa-2,4,6-trienoic acid, which is oxidized to octa-2,4,6-trienedioic acid by Tri23. An uncharacterized CoA ligase transforms dicarboxylic acid into its CoA form to be utilized by Tri3 and Tri18 to afford the acylated product 54. Importantly, 55 also serves as the key precursor of many other acylated trichothecenes with diverse side chains, including crotocin (56) [59], baccharin (baccharinoid B5) (57) [60], roridin A (58) [61], and satratoxin H (39) [62] (Fig. 5C).

\section{Dioxafenestrane sesquiterpenoids}

The dioxafenestrane sesquiterpenoid pathways provide another example in which fungal sesquiterpenoids are generated in branching pathways (Fig. 6) [63, 64]. The biosyntheses of penifulvins and asperaculins both begin with the cyclization of FPP into the sesquiterpene silphinene (59), which is synthesized by the terpene cyclase PeniA/AspeG. Subsequently, the P450 PeniB/AspeF performs a series of oxidative reactions to yield the tetracyclic sesquiterpenoid $\mathbf{6 0}$. Compound $\mathbf{6 0}$ then undergoes Baeyer-Villiger oxidation in both pathways, but an oxygen atom is inserted at two distinct positions by the FMO, PeniC or AspeB, to provide penifulvin A (61) and 9-deoxyasperaculin A (62), respectively. Interestingly, although PeniC and AspeB, the key enzymes for the pathway divergence in the dioxafenestrane sesquiterpenoid biosynthesis, are both FMOs, they are phylogenetically distantly related to each other. In the late-stage of biosynthesis, 61 is converted into penifulvin $G(63)$ by two $\alpha$ KG-dependent dioxygenases PeniD and PeniF and the acetyltransferase PeniE, whereas AspeC and AspeD, which are PeniF and PeniD homologues, respectively, oxidize 62 to form asperaculin $C(64)$.

\section{Fusidane antibiotics}

Fusidane antibiotics are fungal tetracyclic triterpenoids that inhibit bacterial protein biosynthesis [65], and fusidic acid (65), a representative fusidane antibiotic, has been utilized as an antibiotic mainly for staphylococcal infections [66]. Among fusidane antibiotics, the complete biosynthetic pathway of helvolic acid (66) was initially elucidated, which facilitated the biosynthesis studies of 


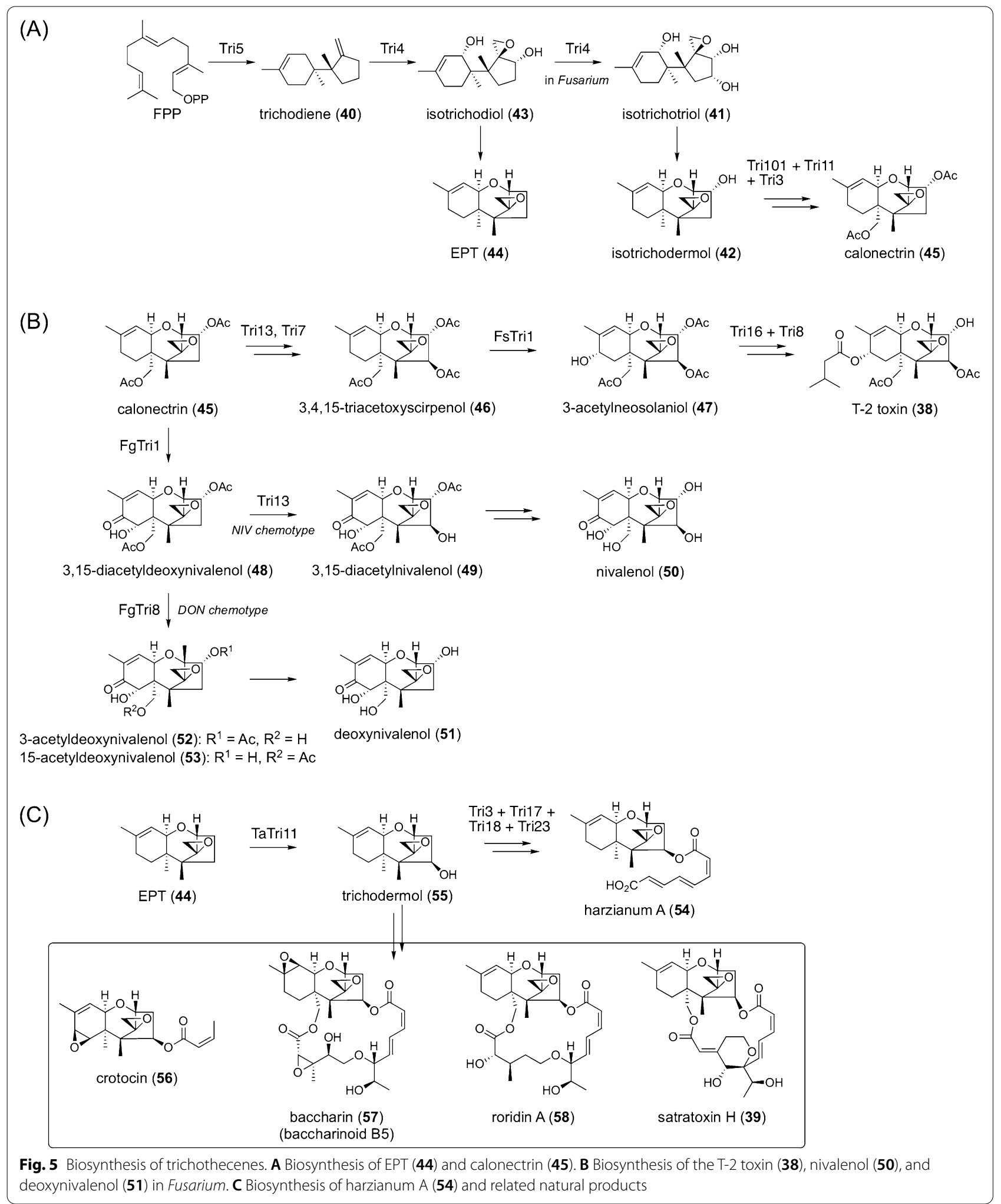




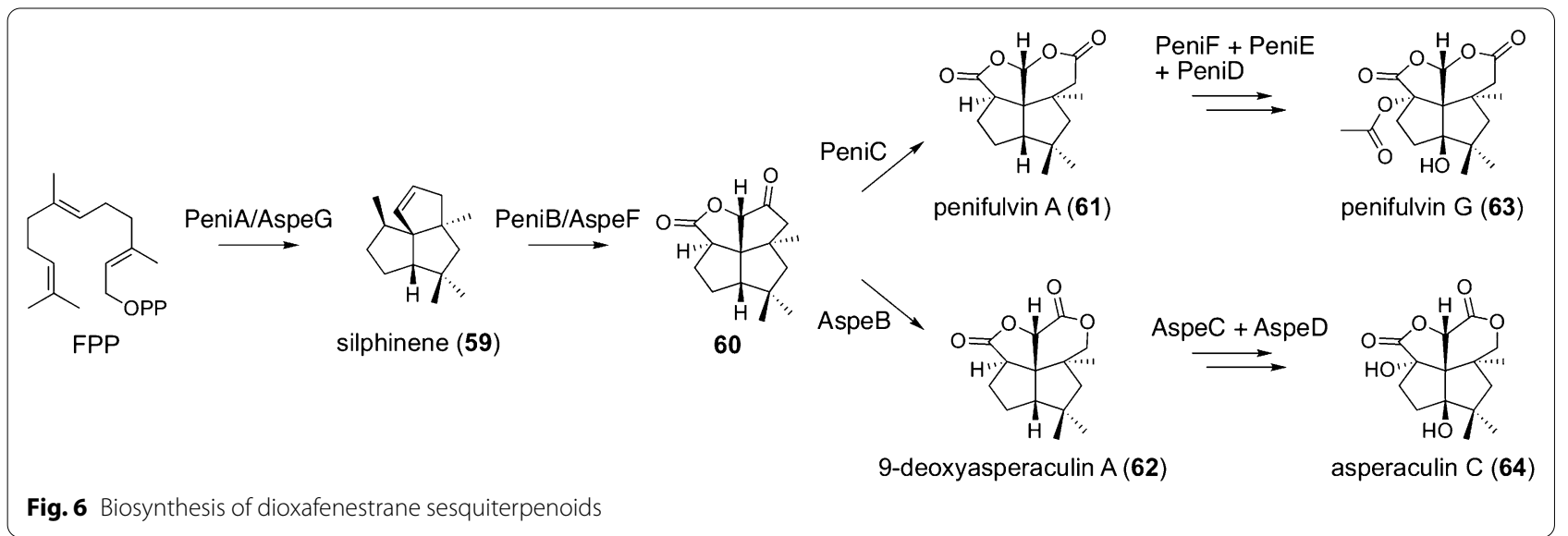

other members, such as 65 and cephalosporin $\mathrm{P}_{1}(\mathbf{6 7})$. In the fusidane antibiotic biosynthetic process (Fig. 7), (3S)2,3-oxidosqualene is first cyclized by an oxidosqualene cyclase (HelA in the helvolic acid pathway) to generate the tetracyclic triterpene alcohol protosta-17(20)Z,24dien-3 $\beta$-ol (68) [67]. This triterpene alcohol undergoes several tailoring reactions to provide a common precursor for 65, 66, and 67 with the fusidane skeleton [68-70]; this transformation involves the three P450s, HelB1, HelB2, and HelB4, the acetyltransferase HelD2, and the SDR HelC in helvolic acid biosynthesis. The common intermediate 69 is accepted by the P450 HelB3, the acetyltransferase HelD1, and the 3 -ketosteroid- $\Delta^{1}$ dehydrogenase HelE to afford $\mathbf{6 6}$ in Aspergillus fumigatus [68], whereas it is converted to $\mathbf{6 7}$ by the SDR CepC2, the P450 CepB4, and the acetyltransferase CepD2 in Acremonium chrysogenum [70]. The biosynthesis of $\mathbf{6 5}$ in Acremonium fusidioides requires the P450 FusB1 and the SDR FusC1 [69]. Interestingly, another SDR FusC2, which is a HelC homologue, accepts the same substrate

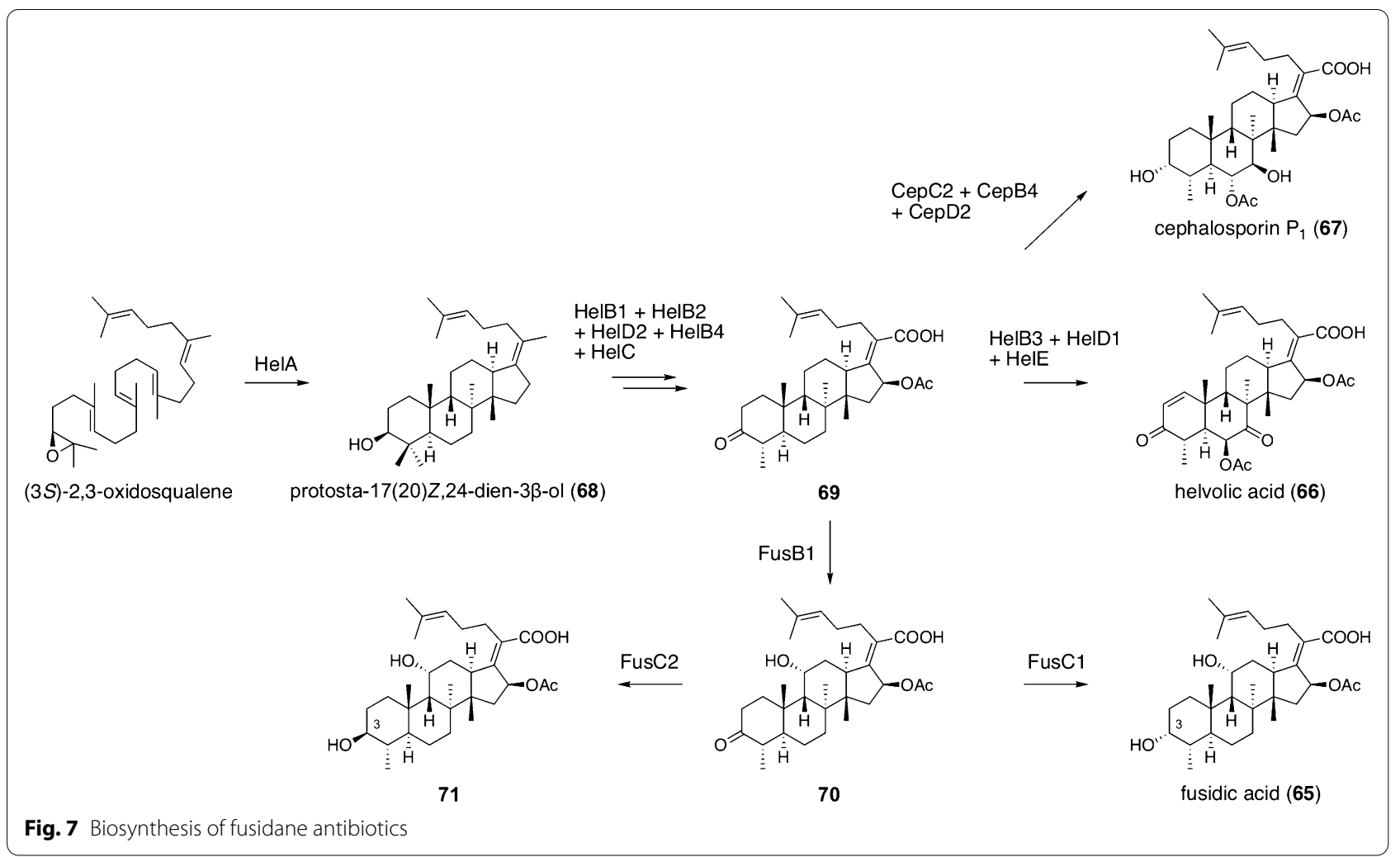


as FusC1, 70, to generate 71, the C-3 epimer of 65 with a (3S)-hydroxy group [69]. However, in the coexistence of FusC1 and FusC2, FusC1 works much more efficiently than FusC2, and therefore, $\mathbf{6 5}$ is the dominant end product in A. fusidioides.

\section{Meroterpenoids}

Meroterpenoids are natural hybrid products that are in part derived from terpenoid biosynthesis and ubiquitously distributed both in primary and secondary metabolism [71-73]. Fungi are especially prolific producers of meroterpenoids, and fungal meroterpenoids exhibit enormous structural diversity, often with complicated molecular architectures and a broad range of biological activities. Fungal meroterpenoid biosynthesis occurs in a highly branching manner, and branching can be observed at different biosynthesis stages, thus allowing for the biogenesis of diverse metabolites from a small number of starting materials.

One of the most intensively studied classes of fungal meroterpenoids comprises those derived from the aromatic polyketide 3,5-dimethylorsellinic acid (72; DMOA), and many DMOA-derived meroterpenoids possess a unique and complicated molecular skeleton (Fig. 8). A key factor generating the structural diversity of DMOA-derived metabolites is the existence of terpene cyclases with different activities. In the biosynthesis of andrastin $\mathrm{A}$, austinol, and terretonin, $(R)$-epoxyfarnesylDMOA methyl ester (73) serves as a common intermediate but is cyclized into different products, generating the biosynthesis branching point (Fig. 9A) [74, 75]. Three terpene cyclases, AdrI, AusL, and Trt1, all accept $\mathbf{7 3}$ as a substrate and cyclize it into the tetracyclic carbocationic species 74; however, in the final step of the reaction, these enzymes perform deprotonation at different positions to yield andrastin $\mathrm{E}(\mathbf{7 5})$, protoaustinoid A (76), and preterretonin A (77), respectively. Intriguingly, the terpene cyclase involved in novofumigatonin biosynthesis utilizes $(S)$-epoxyfarnesyl-DMOA (78) with a free carboxy group as a substrate to form asnovolin $\mathrm{H}(79)$ [76], although methyl-esterification is essential for the activities of AdrI, AusL, and Trt1 [74, 75]. Additionally, based on the cyclized product structures, AdrI, AusL, and Trt1 accept $(R)$-epoxide, whereas $(S)$-epoxide is used by NvfI, indicating the presence of epoxidases with different stereoselectivities. In a recent study by Mitsuhashi et. al., synthetic epoxyfarnesyl-DMOA methyl ester molecules, including unnatural isomers, were reacted with a series of meroterpenoid cyclases, resulting in the production of several new meroterpenoid species generated by new cyclization modes [77]. Thus, enzymes that catalyze cyclization reactions in an unprecedented manner could be further discovered from unelucidated DMOA-derived meroterpenoid pathways.

Pathway branching in DMOA-derived meroterpenoid pathways also occurs at a later biosynthesis stage. Preaustinoid A1 (80) is a common biosynthetic precursor of several meroterpenoids (Fig. 9B), such as austinol, paraherquonin, and berkeleyacetals. The $\alpha$ KG-dependent dioxygenases AusE and AusE', which are involved in the biosynthesis of austinol and acetoxydehydroaustin, respectively, accept $\mathbf{8 0}$ to catalyze two successive oxidations to afford preaustinoid A3 (81) with the characteristic spirolactone system via preaustinoid A2 (82) [78, 79]. Meanwhile, PrhA, a homologue of AusE/AusE', utilizes the same substrate but performs a distinct oxidative rearrangement to yield berkeleydione (83) harboring the cycloheptadiene core via berkeleyone B (84) [79]. Intriguingly, AusE' and PrhA share $>90 \%$ sequence identity, and a structural biology study revealed that only three amino acid residues in the enzyme active site are crucial for product selectivity [80]. Andiconin (85) serves

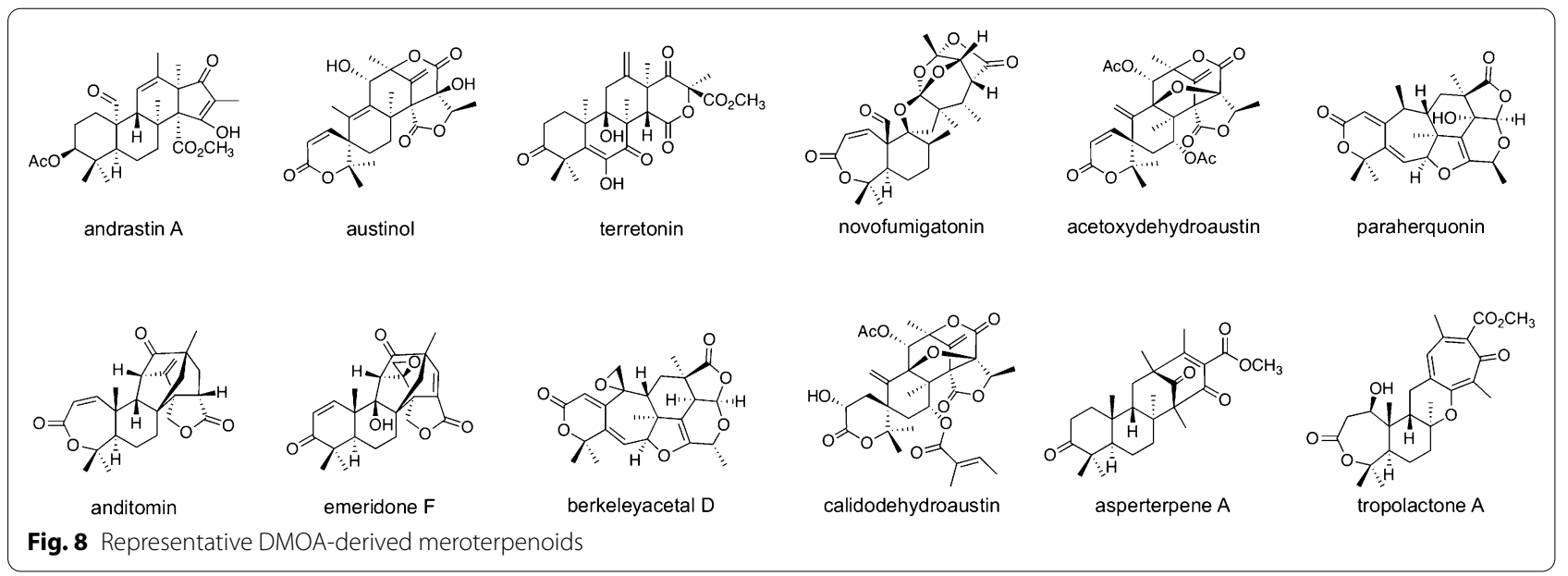




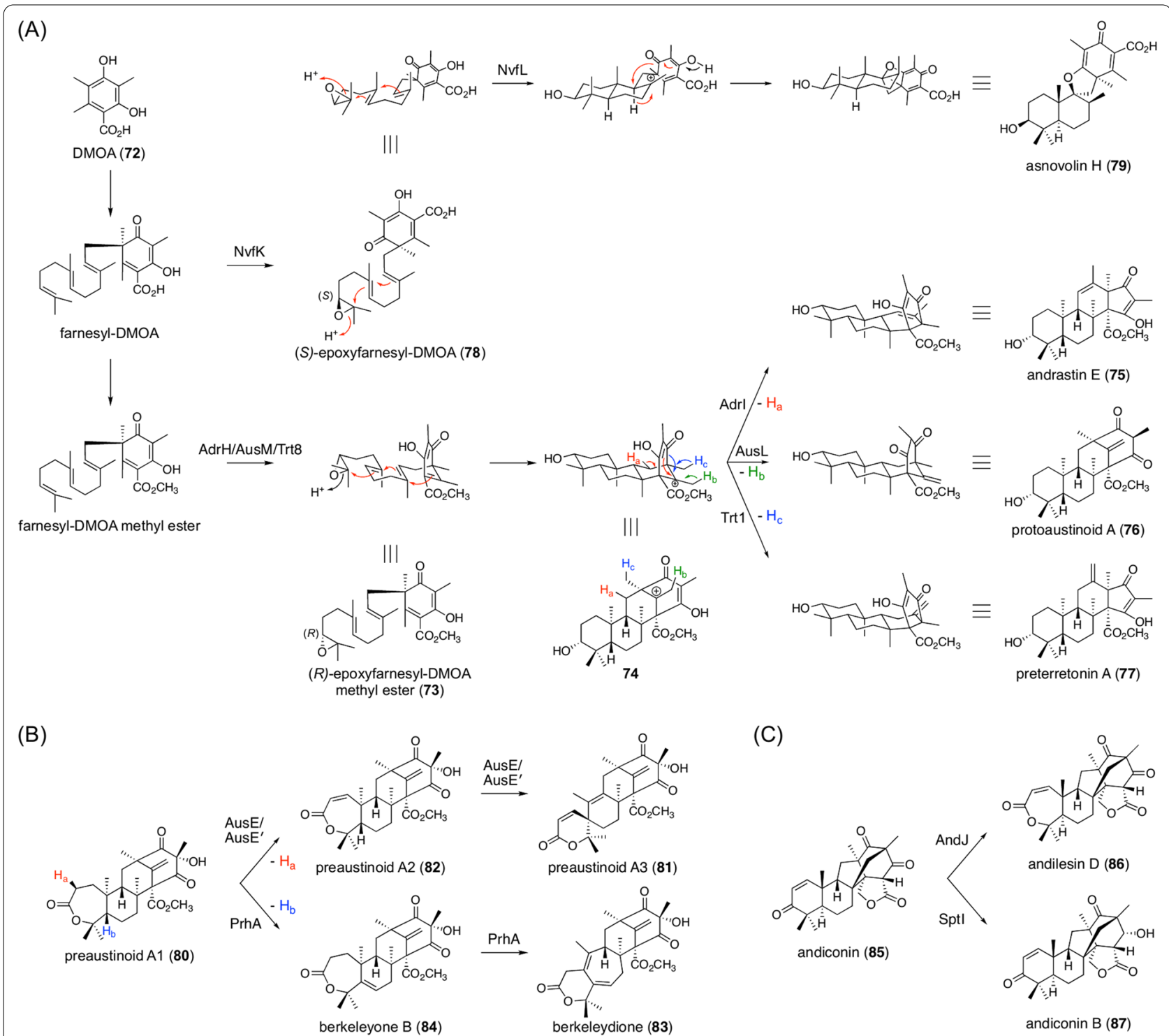

Fig. 9 Pathway branching in the biosynthesis of DMOA-derived meroterpenoids. A Reactions catalyzed by terpene cyclases. B Reactions catalyzed by AusE/AusE' and PrhA. C Reactions catalyzed by AndJ and Sptl

as a common biosynthetic intermediate of anditomin and emeridone F (Fig. 9C) [81, 82]. In the anditomin pathway, AndJ, which acts as a Baeyer-Villiger monooxygenase, transforms 85 into andilesin D (86) with a seven-membered lactone ring [81]. Emeridone biosynthesis lacks an AndJ homologue, and $\mathbf{8 5}$ is accepted by the SDR SptI to be converted to andiconin B (87) [82]. It should be noted that the SptI homologue in the anditomin pathway, AndI, does not accept $\mathbf{8 5}$ as a substrate but acts only after the AndJ-catalyzed reaction.

Polyketides other than DMOA can also be employed as the non-terpenoid portion of fungal meroterpenoids. Orsellinic acid serves as the precursor of diverse fungal meroterpenoids such as ascofuranone (88), ascochlorin (89), chartarlactam A (90), stachybisbin B (91), and SMTP-0 (92) (Fig. 10). Among these metabolites, the complete biosynthetic pathways of $\mathbf{8 8}$ and $\mathbf{8 9}$ have recently been elucidated [83], exemplifying pathway branching occurring in a single fungus. In the biosynthesis of these two meroterpenoids, orsellinic acid is converted to ilicicolin A epoxide (93) as a common precursor via ilicicolin B (94), which is also a biosynthetic intermediate of many other orsellinate-derived fungal meroterpenoids [84]. In the ascochlorin pathway, the terpene cyclase AscF cyclizes the farnesyl moiety of $\mathbf{9 3}$ to provide ilicicolin $\mathrm{C}(\mathbf{9 5})$ with a cyclohexanone ring, 


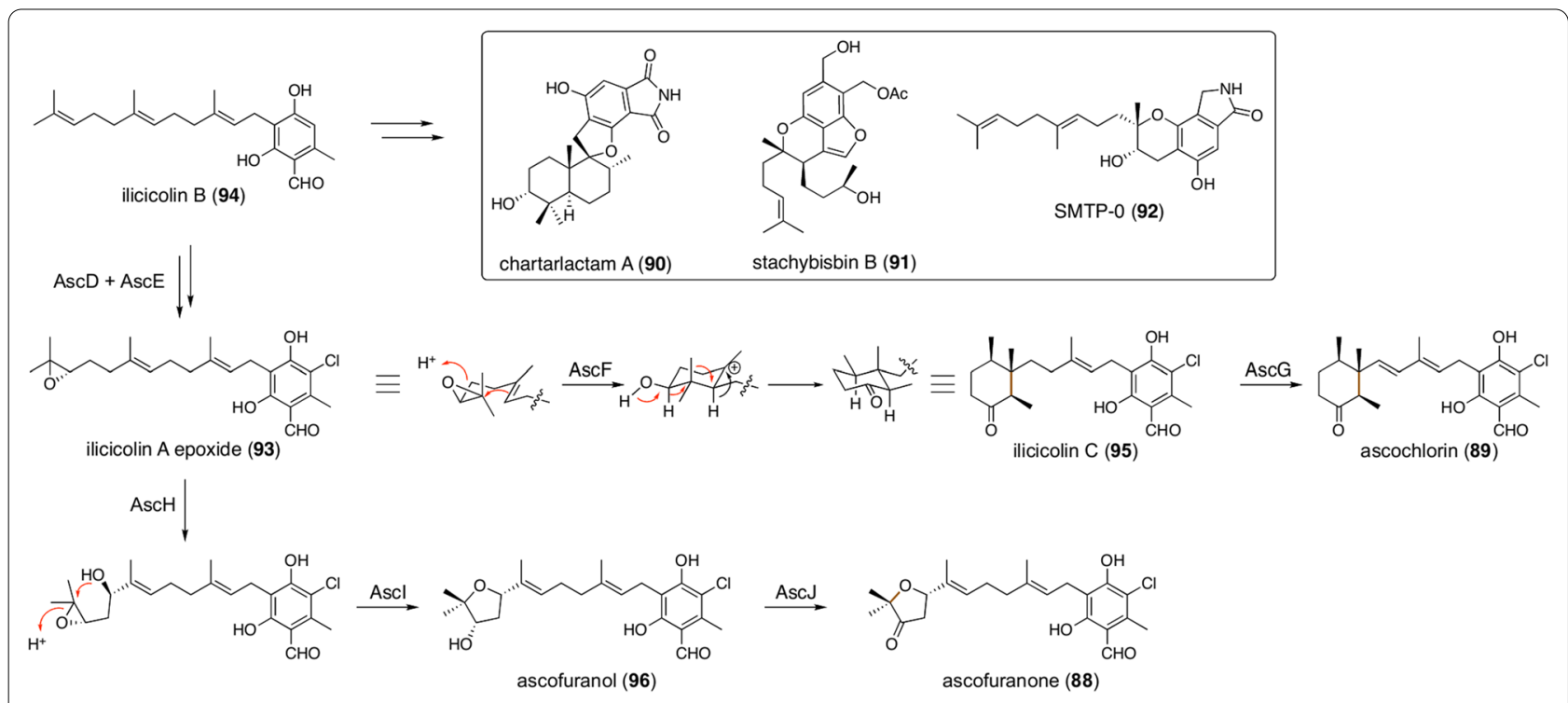

Fig. 10 Biosynthesis of ilicicolin B-derived meroterpenoids

which subsequently undergoes dehydrogenation catalyzed by the P450 AscG to yield 89. Ascofuranone biosynthesis involves three dedicated enzymes encoded by a separate gene cluster from that of $\mathbf{8 9}$. In this process, 93 is first hydroxylated by the $\mathrm{P} 450 \mathrm{AscH}$, followed by heterocyclization catalyzed by AscI to generate ascofuranol (96). Interestingly, AscI does not display sequence similarity with AscF and the terpene cyclases involved in the DMOA-derived metabolite pathways but is homologous to CtvD and AurD, the epoxide hydrolases involved in the biosynthesis of citreoviridin and aurovertin, respectively $[85,86]$. Finally, the SDR AscJ performs an alcohol dehydrogenation reaction to complete the biosynthesis.

Triacetic acid lactone (97; TAL) is another polyketide used as a fungal meroterpenoid building block. In the biosynthetic processes of known TAL-derived meroterpenoids, 97 undergoes geranylgeranylation and epoxidation to provide a substrate for terpene cyclases, 98 (Fig. 11) [87]. Chevalone biosynthesis adopts the terpene cyclase Cle3 to yield the pentacyclic product chevalone E (99), whereas Sre3, which is responsible for the sartorypyrone pathway, synthesizes sartorypyrone D (100), which possesses the monocyclic terpenoid moiety. The terpene cyclase for aszonapyrone biosynthesis appears to have another function in producing the tetracyclic aszonapyrone B (101) [88]; however, this function has yet to be identified.

Another example in which terpene cyclases are responsible for pathway divergence can be found in the biosynthesis of chrodrimanins and talaromyolides (Fig. 12) [89,

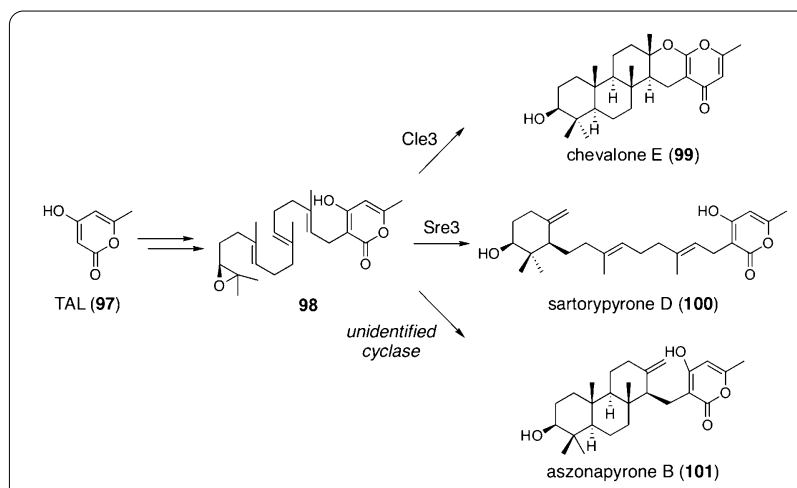

Fig. 11 Terpene cyclases involved in the biosynthesis of TAL-derived meroterpenoids

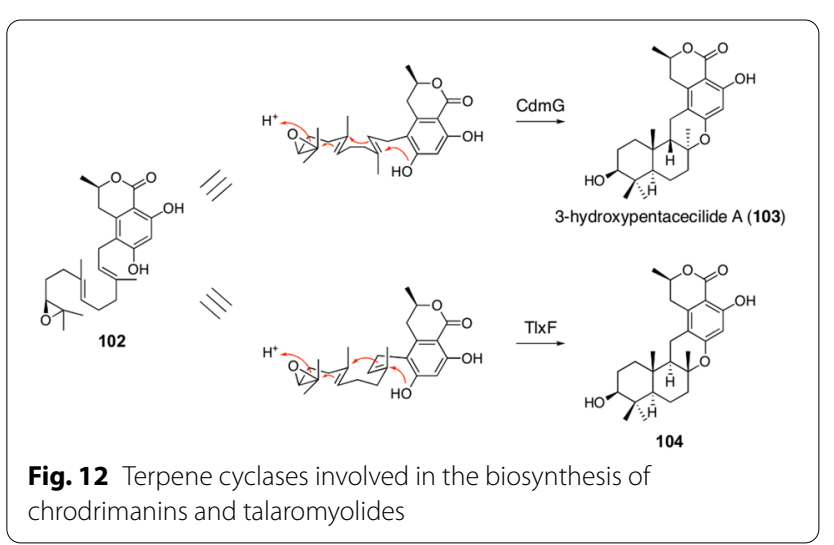


90]. Both biosynthetic pathways adopt the identical precyclized intermediate $\mathbf{1 0 2}$ derived from the polyketide 6-hydroxymellein; however, terpene cyclization occurs in different ways. In chrodrimanin biosynthesis, the terpene cyclase CdmG folds the farnesyl moiety in the chair-boat conformation to yield 3-hydroxypentacecilide A (103), whereas TlxF involved in the talaromyolides pathway performs chair-chair cyclization to give $\mathbf{1 0 4}$.

A methylated analogue of TAL (97), 5-methyl TAL (105), is often found in fungal meroterpenoid structures, and in recent years, the complete biosynthetic pathways of several 5-methyl TAL-derived meroterpenoids have been revealed (Fig. 13) [91-93]. In the biosynthesis of setosusin (106), 105 undergoes a series of reactions similar to those in TAL-derived meroterpenoid pathways to provide a precyclized intermediate 107 , which is accepted by the terpene cyclase SetH to give $\mathbf{1 0 8}$ with a tricyclic terpenoid portion [93]. This cyclized product is also used as the precursor for other fungal metabolites, such as brevione E (109) [94], although brevione E biosynthetic genes have not been reported. The biosynthesis of other 5-methyl TAL-derived meroterpenoids, such as subglutinols, higginsianins, and metarhizins, branches from the setosusin/brevione pathways at an early biosynthesis stage. In the biosynthetic processes of these molecules, epoxidation occurs at the second double bond from the geranylgeranyl chain terminus of $\mathbf{1 1 0}$ to afford 111, which is cyclized into metarhizin $C(\mathbf{1 1 2})$ with a bicyclic terpenoid moiety. In a recent study by Tsukada et. al. [92], biosynthetic genes for metarhizin C-derived metabolites from five fungal species were examined and heterologously expressed, leading to the production of several known and new meroterpenoids. The FADdependent oxidoreductase $\operatorname{DpxxF}(\mathrm{xx}=\mathrm{ma}$, as, or $\mathrm{ch})$ conducts oxidative cyclization to synthesize subglutinols A (113) and B (114) from 112. DpasF or DpchF can also install a carbonyl group onto the dimethylallyl portion of $\mathbf{1 1 2}$ to yield a previously undescribed meroterpenoid 115. The SDRs DpxxG and DpxxH ( $x x=f g, m p$, or $c h)$ invert the stereochemistry of $\mathbf{1 1 2}$ at the $C-8$ position to give higginsianin $B$ (116). Compound 116 is oxidized by DpasF or DpchF to provide higginsianin A (117), which is the $\mathrm{C}-8$ epimer of $\mathbf{1 1 3}$. Compound $\mathbf{1 1 6}$ also serves as the precursor for three new meroterpenoids 118-120, which are synthesized by catalysis of the methyltransferase DpfgI or DpmpI, the P450 DpfgJ or DpmpJ, and the methyltransferase DpfgK.

Although the majority of fungal meroterpenoids originate from polyketide and terpenoid pathways, non-polyketide molecules can also be observed in meroterpenoid structures as non-terpenoid moieties. Indole diterpenoids are a large group of fungal meroterpenoids lacking

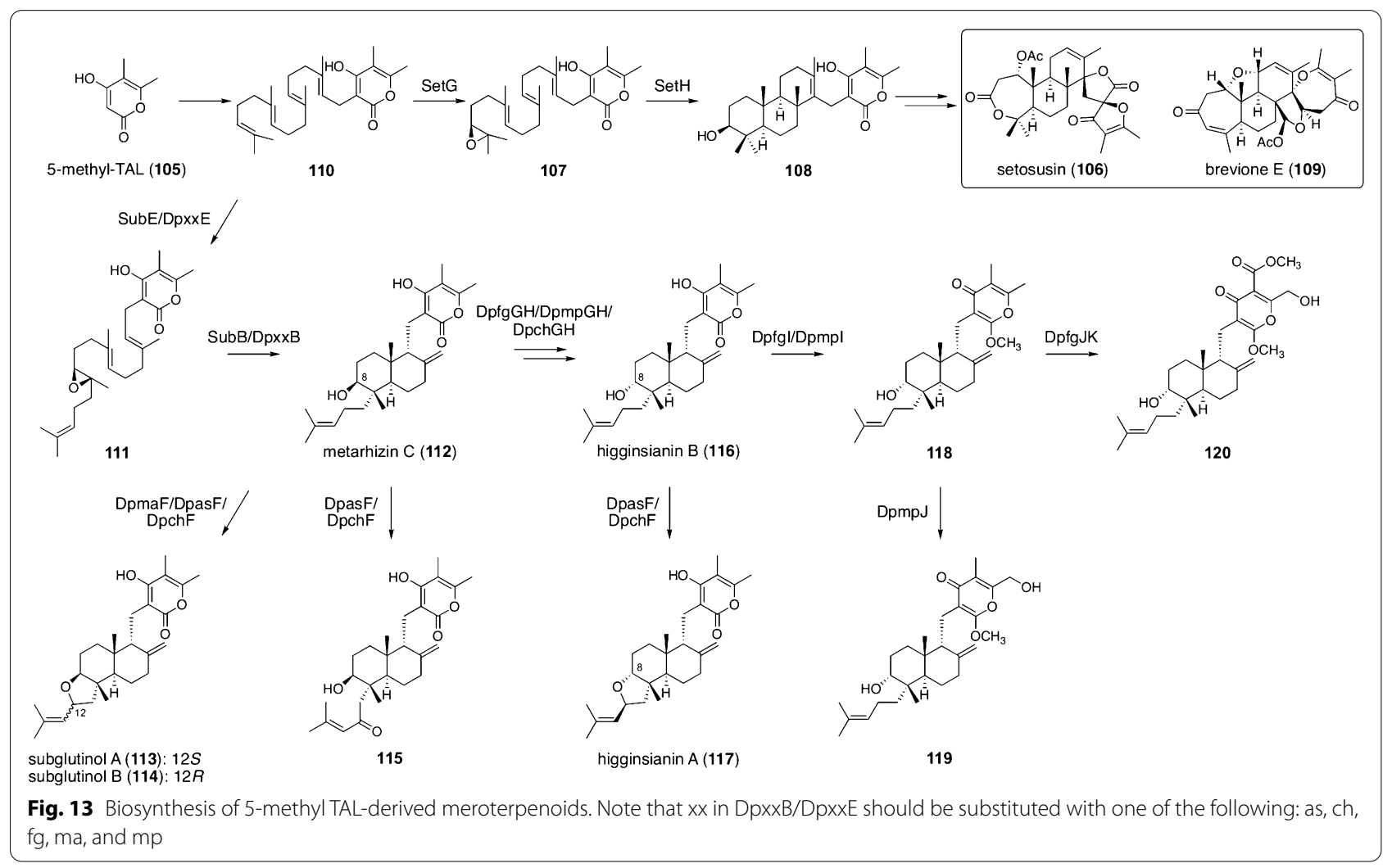


a polyketide portion; instead, they possess an indole ring as a non-terpenoid moiety [95]. As observed in the biosynthesis of polyketide-derived meroterpenoids, the terpenoid chain cyclization mode contributes to the structural diversity of indole diterpenoids [96]. However, the majority of indole diterpenoids are biosynthesized via the hexacyclic molecule paspaline (121) (Fig. 14), which is generated from indole-3-glycerol phosphate by four dedicated enzymes [97, 98]. In an indole diterpenoid biosynthesis branch, $\mathbf{1 2 1}$ is transformed into paxilline (122) by the catalysis of two P450s, PaxP and PaxQ [97]. Compound 122 further undergoes highly complicated tailoring reactions to provide penitrem A (123) [99]. The PaxP product 13-desoxypaxilline (124) also serves as a precursor of other indole diterpenoids, such as aflatrems and shearinines. In aflatrem biosynthesis, $\mathbf{1 2 4}$ is oxidized by the P450 AtmQ to afford paspalinine (125), which is further converted to aflatrem (126) and its isomer $\beta$-aflatrem (127) by the dimethylallyltryptophan synthase (DMATS)-type prenyltransferase AtmD [100-102]. JanD, an AtmD homologue involved in the biosynthesis of shearinine D (128), also accepts 125 as a substrate but performs diprenylatation to give shearinine K (129) [103], which undergoes oxidative tailoring reactions by the FMO JanO and the P450 JanJ to complete biosynthesis [104]. Meanwhile, the biosynthesis of lolitrem B (130) branches from the other pathways mentioned above just after paspaline formation. The P450 LtmQ, which is homologous to PaxQ and AtmQ, performs hydroxylation to provide terpendole $\mathrm{E}(\mathbf{1 3 1})[105,106]$. Compound 131 is subsequently transformed into terpendole $C(\mathbf{1 3 2})$ by four enzymes, and finally, $\mathbf{1 3 0}$ is synthesized by the prenyltransferase LtmE and the P450 LtmJ from 132 [107, 108]. In Chaunopycnis alba, an uncharacterized dehydrogenase oxidizes 132 to yield terpendole K (133) [106].

\section{Converging pathways}

Heterodimeric compounds, which are formed by the fusion of two metabolites derived from two distinct pathways, are often obtained during natural product isolation. Most heterodimeric natural products are often spontaneously formed due to reactive structural elements in the monomeric natural products that compose the heterodimer. However, in some biosynthetic processes, two or more compounds synthesized via separate pathways undergo an enzyme-catalyzed fusion reaction, expanding the structural diversity of natural products. This

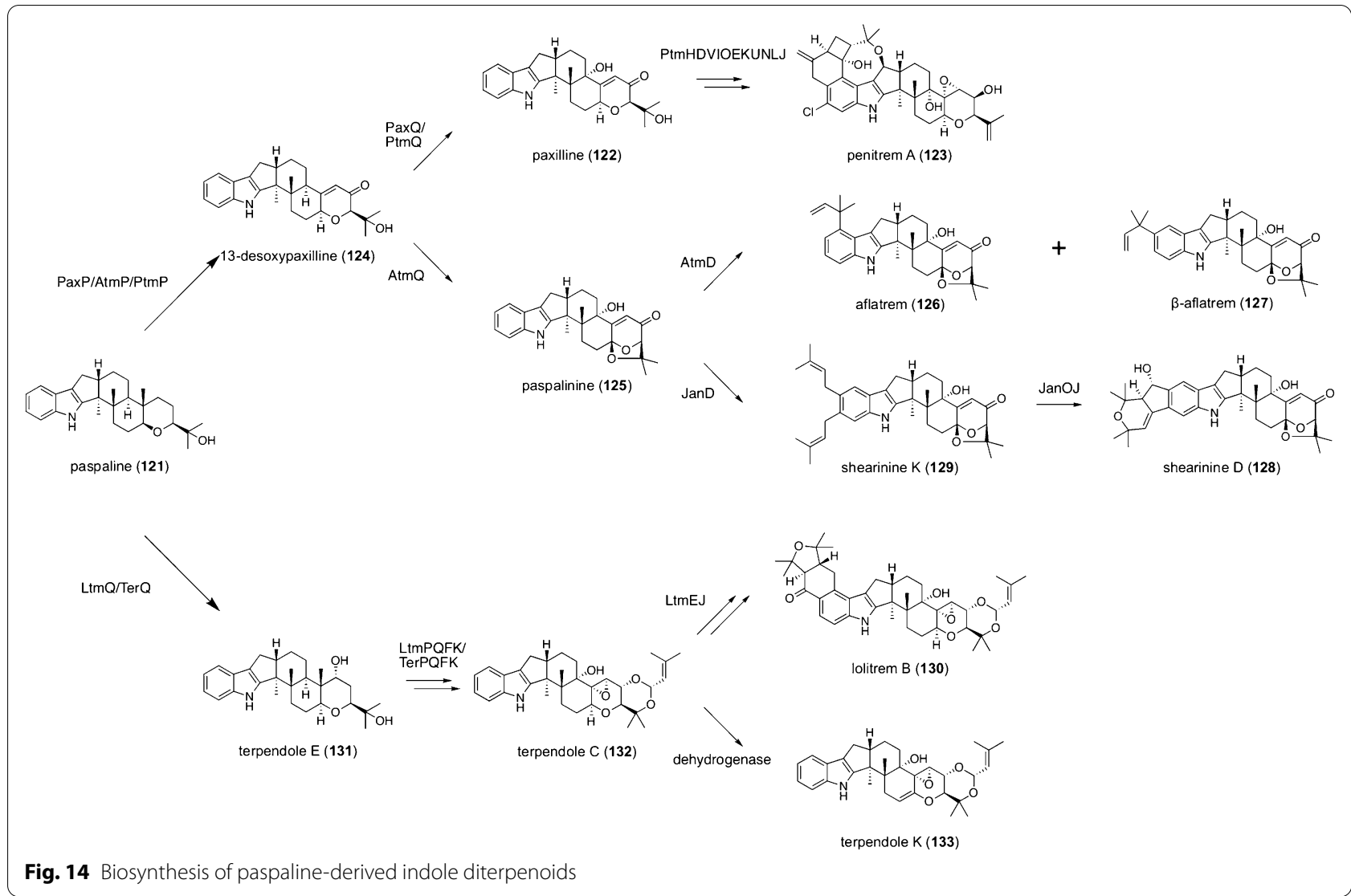


section summarizes representative converging pathways observed in fungal natural product biosynthesis and the enzymes responsible for the hybridization of two distinct natural products.

\section{Addition of a polyketide chain}

One representative converging pathway in fungal natural product biosynthesis is the addition of a polyketide chain to a molecule synthesized in a separate biosynthetic route. One example is the biosynthesis of harzianum A (54), as mentioned above (Fig. 5C) [58], and similar reactions to attach a polyketide chain are found in many fungal natural product pathways (Fig. 15). In the last step of lovastatin biosynthesis, the acyltransferase LovD transfers the polyketide chain synthesized by the PKS LovF to introduce a methylbutanoyl moiety to monacolin $\mathrm{J}$ acid (134) to yield lovastatin acid (135) (Fig. 15A) [109]. Squalestatin biosynthesis involves the acyltransferase Mfm4 that utilizes the tetraketide CoA $\mathbf{1 3 6}$ as a substrate to yield squalestatin S1 (137); 136 is synthesized by the PKS squalestatin tetraketide synthase (SQTKS) and the CoA ligase Mfm9 (Fig. 15B) [110, 111]. In fungal meroterpenoid calidodehydroaustin biosynthesis (Fig. 8), the acyltransferase AusQ performs a transacylation reaction by utilizing the polyketide chain generated by the PKS AusV to give precalidodehydroaustin (138) from 1,2-dihydro-7-hydroxydehydroaustin (139) (Fig. 15C) [112]. AusQ is also known to catalyze acetylation reactions at the same position. The biosynthesis of another fungal meroterpenoid, fumagillin, adopts the acyltransferase Fma-AT to install the dodecapentaenoyl moiety, which is synthesized by the PKS Fma-PKS, onto fumagillol (140) to produce prefumagillin (141) (Fig. 15D) [113].

Calbistrins are structurally similar to lovastatin in that they have a polyketide chain attached to a decalin core; however, the biosynthesis of calbistrins and lovastatin somewhat differs. CalD, the enzyme responsible for the acylation reaction in the calbistrin pathway, performs a similar reaction to LovD to introduce the hexaketide moiety to decumbenone A (142) to yield 143 (Fig. 15E), although CalD does not exhibit sequence similarity with LovD [114]. Interestingly, the calbistrin biosynthetic gene cluster encodes a LovD homologue, CalJ, which is unable to perform acylation reactions but instead catalyzes the hydrolysis of the ester bond formed by the
(A)

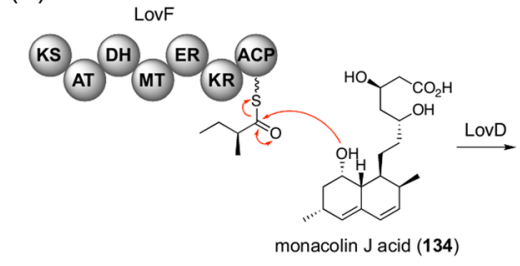

(C)

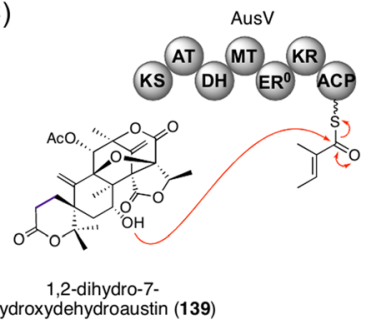

(E)

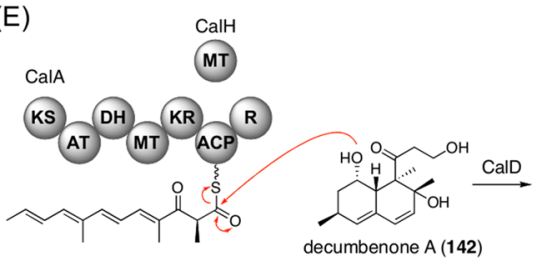

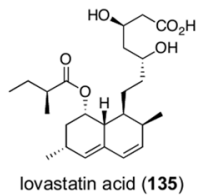

lovastatin acid (135)

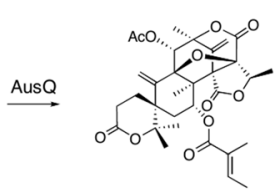

(B)

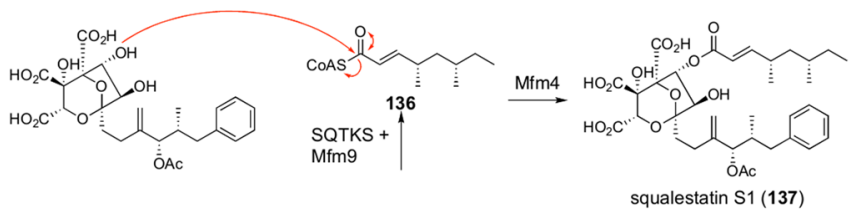

(D)
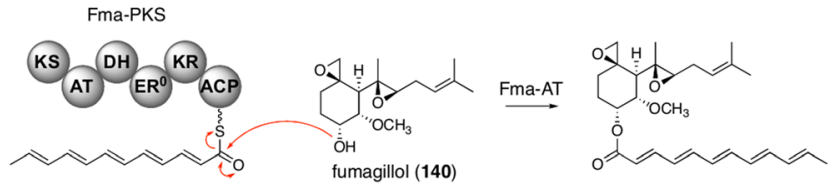

prefumagillin (141)

(F)
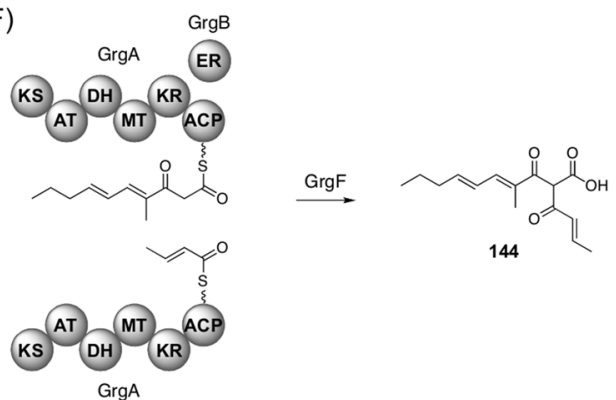

Fig. 15 Additions of a polyketide chain during fungal natural product biosynthesis. Reactions catalyzed by $\mathbf{A} L$ LovD, B Mfm4, C AusQ, D Fma-AT, E CalD, and $\mathbf{F}$ GrgF 
CalD-catalyzed reaction. Another intriguing feature of calbistrin biosynthesis is that both the decalin and polyene portions are generated from the single PKS CalA. The decalin portion is synthesized in a CalA and transacting enoylreductase (trans-ER) CalK collaboration, whereas the polyene hexaketide is formed by CalA and the trans-acting methyltransferase CalH. Thus, the PKS CalA contributes both to pathway branching and convergence in the biogenesis of calbistrins.

Gregatin biosynthesis provides a similar example in which a single PKS is responsible for the synthesis of two distinct polyketide chains that are eventually fused together (Fig. 15F) [115]. GrgA, the PKS involved in the gregatin pathway, synthesizes the longer pentaketide chain in the presence of the trans-ER GrgB, whereas it produces a shorter diketide chain when $\mathrm{GrgB}$ is absent. These two polyketide chains are fused by the $\alpha / \beta$ hydrolase fold enzyme GrgF to generate $\mathbf{1 4 4}$.
Incorporation of non-proteinogenic amino acids into NRPS assembly lines

One key feature of nonribosomal peptide biosynthesis, distinct from that of ribosomal synthesis, is that nonproteinogenic amino acids and non-amino acid molecules can be directly used as building blocks for peptide chain synthesis [116]. Non-standard amino acids found in nonribosomal peptides are often synthesized by dedicated enzymes prior to acceptance by the NRPS assembly line, thus exemplifying converging pathways in natural product biosynthesis.

Pneumocandin $\mathrm{A}_{0}$ biosynthesis is one of the most complicated examples in which the dedicated syntheses of unusual amino acids are required (Fig. 16). Pneumocandin $\mathrm{A}_{0}(\mathbf{1 4 5})$ is an antifungal agent in the echinocandin class, obtained from the fungus Glarea lozoyensis [117]. Pneumocandin $\mathrm{A}_{0}$ biosynthesis is initiated with the synthesis of dimethylmyristoyl-CoA

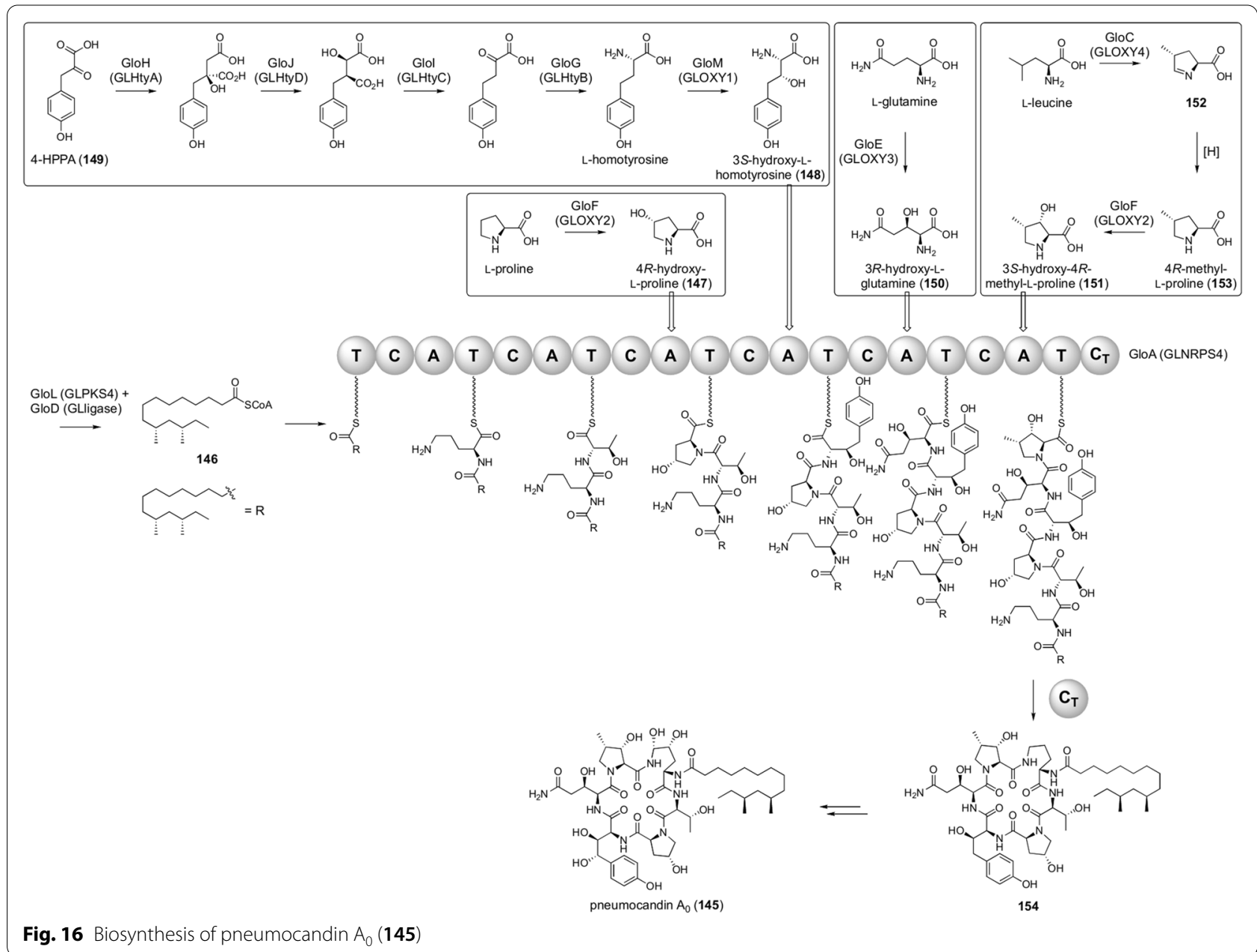


(146) by the PKS GloL (GLPKS4) and the CoA ligase GloD (GLligase), and 146 is loaded onto the NRPS GloA (GLNRPS4) as a starter unit for peptide chain synthesis [118, 119]. GloA consists of six modules, five of which accept a non-proteinogenic amino acid. Among these five non-proteinogenic amino acids, ornithine, accepted by the first A domain, is an important primary metabolite sufficiently present in cells. However, the remaining four amino acids need to be prepared by utilizing dedicated enzymes encoded by the pneumocandin biosynthetic gene cluster. The third A domain activates $4 R$-hydroxy-L-proline (147), which is synthesized by L-proline hydroxylation catalyzed by the $\alpha$ KG-dependent dioxygenase GloF (GLOXY2) [120]. The fourth A domain accepts 3S-hydroxy-L-homotyrosine (148), which is synthesized from 4-hydroxyphenylpyruvic acid (149; 4-HPPA) by five enzymes, GloH, -J, -I, -G, and -M (GLHtyA, -HtyD, -HtyC, -HtyB, and -OXY1) $[119,121,122]$. The $\alpha K G$-dependent dioxygenase GloE (GLOXY3) hydroxylates L-glutamine to provide 3R-hydroxy-L-glutamine (150) [123], which is loaded onto the fifth module. The sixth A domain substrate, $3 S$-hydroxy-4R-methyl-L-proline (151), is generated from L-leucine. In this transformation, L-leucine is oxidized by the $\alpha \mathrm{KG}$-dependent dioxygenase GloC (GLOXY4), and the resultant cyclic imine $\mathbf{1 5 2}$ is reduced to $4 R$-methyl-L-proline (153) by an uncharacterized enzyme $[119,122]$. GloF, which is also used in
4R-hydroxy-L-proline synthesis, hydroxylates 153 to yield 151 [120]. The linear peptide chain synthesized by GloA undergoes $\mathrm{C}_{\mathrm{T}}$ domain-catalyzed cyclization to be released from the NRPS enzyme to provide the cyclic peptide 154. The cyclic peptide undergoes further oxidative tailoring reactions to finally provide $\mathbf{1 4 5}$. Similar biosynthetic strategies incorporating unusual amino acids or starter units are also found in other fungal NRPS pathways, such as the biosynthesis of echinocandins [121, 122] and leucinostatins [124].

Some fungal PKS-NRPS hybrids also accept an unusual amino acid synthesized by dedicated enzymes encoded by a gene cluster containing the PKS-NRPS gene (Fig. 17). In the biosynthesis of Sch 210972 (155), $\gamma$-hydroxymethyl-L-glutamic acid (156) is accepted by the PKS-NRPS CghG A domain (Fig. 17A) [125]. The biosynthesis of this non-proteinogenic amino acid involves the condensation of two pyruvic acid molecules catalyzed by the aldolase $\mathrm{CghB}$, followed by a stereoselective transamination reaction. It has been proposed that transamination is performed by a transaminase encoded outside the biosynthetic gene cluster. Another similar example is found in the biosynthesis of oxaleimides, in which the PKS-NRPS PoxE utilizes $(S, E)$-2-aminodec4-enoic acid (157) as a substrate of the A domain to yield 158 (Fig. 17B) [126]. The amino acid backbone structure is generated by the PKS PoxF, which is modified by the P450 PoxM and the aminotransferase PoxL.
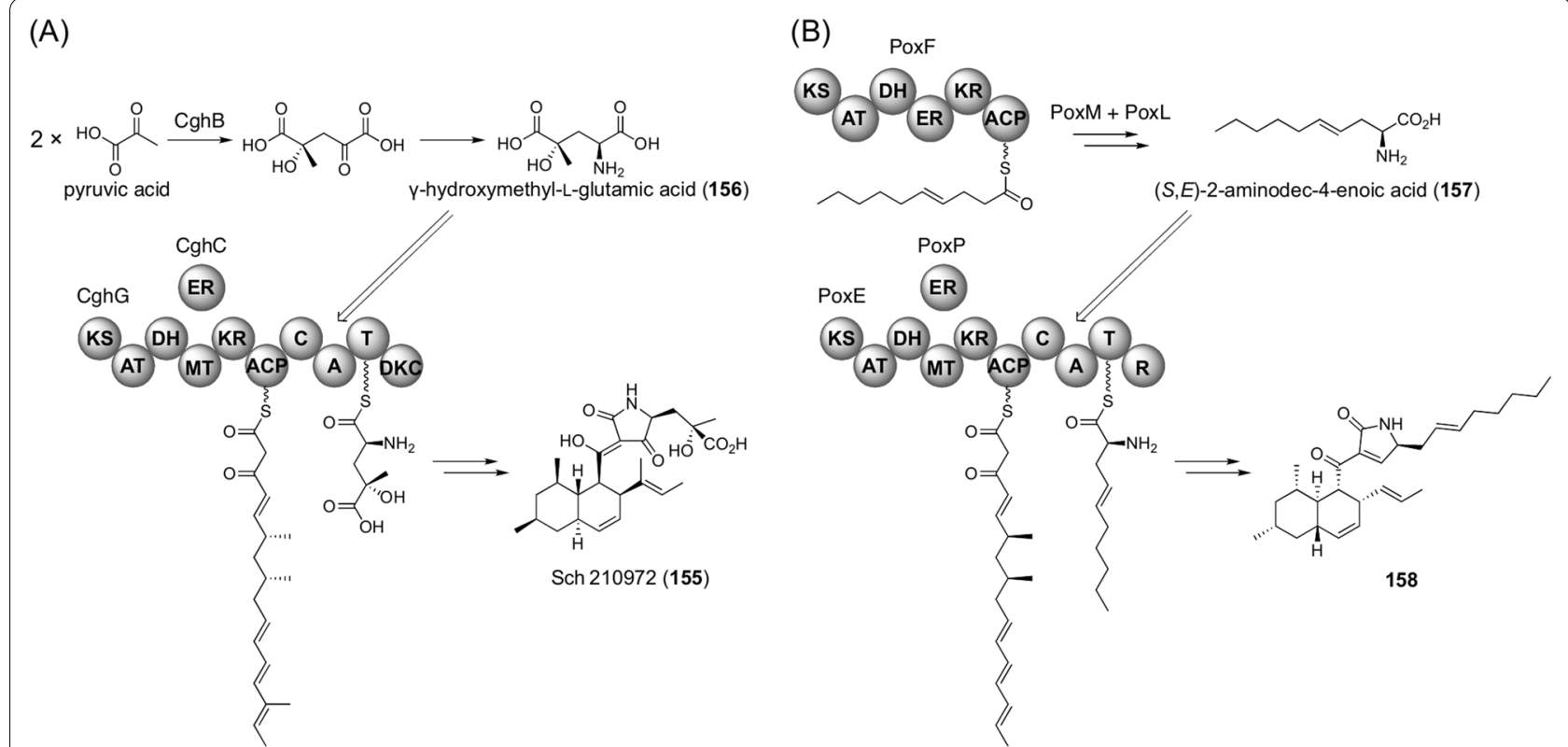

Fig. 17 Biosynthesis of fungal polyketide-nonribosomal peptide hybrids with a non-proteinogenic amino acid moiety. A Biosynthesis of Sch 210972 (151). B Early-stage biosynthesis of oxaleimides 


\section{Communesin B}

Communesins are dimeric indole alkaloids isolated from Penicillium fungi [127-130]. Some of them, such as communesin B (159), harbor the hexadienoyl moiety, which originates from the polyketide pathway. The communesin pathway involves both pathway branching and convergence to furnish the unique molecular architecture $[131,132]$. The communesin core structure is derived from two L-tryptophan molecules, each undergoing different pathways to provide monomeric units of communesins (Fig. 18) [131]. In one branch, L-tryptophan is converted to tryptamine (160) by the tryptophan decarboxylase CnsB. L-Tryptophan is also transformed into aurantioclavine (161) via 4-dimethylallyl-L-tryptophan (162; 4-L-DMAT) by catalysis with the DMATS CnsF, the FMO CnsA, and the catalase CnsD. In the subsequent biosynthetic step, 160 and 161 undergo an oxidative coupling reaction catalyzed by the $\mathrm{P} 450 \mathrm{CnsC}$ to afford the communesin backbone structure 163 [132], which is further converted to communesin I (164) by the methyltransferase CnsE and the $\alpha \mathrm{KG}$-dependent dioxygenase $\mathrm{CnsJ}$. Finally, the acyltransferase $\mathrm{CnsC}$ performs $\mathrm{N}$-acylation by utilizing the hexadienoyl chain synthesized by the PKS CnsI to yield 159.

\section{Flavunoidine}

Flavunoidine (165) is obtained by genome mining in the fungus Aspergillus flavus and features a sesquiterpenoid core modified with dimethylcadaverine (166) and 5,5-dimethyl-L-pipecolic acid (167) [133]. It is a rare example of terpenoid-amino acid conjugated natural products. Compound $\mathbf{1 6 5}$ is generated by the fusion of three separately synthesized building blocks (Fig. 19). In one of the three pathways, L-lysine is converted into 166 by the $N$-methyltransferase $\mathrm{FlvH}$ and the decarboxylase
FlvG. Meanwhile, the terpene cyclase FlvE cyclizes FPP into $(1 R, 4 R, 5 S)-(+)$-acoradiene (168). The P450 FlvD accepts the sesquiterpene hydrocarbon 168 as a substrate to transform it into $\mathbf{1 6 9}$ with a tetracyclic cage. The sesquiterpenoid is further oxidized to the carbocationic species 170, which then reacts with 166; this nucleophilic addition is mediated by the terpene cyclase-like enzyme FlvF. This hybrid molecule $\mathbf{1 7 1}$ is hydroxylated by the P450 FlvC to generate 172, which is further combined with 167 to yield the end product 165. The unusual amino acid 167 is synthesized from $O$-acetyl-L-homoserine (173) and $\alpha$-ketoisovaleric acid (174) by FlvA, the chimeric protein of PLP-dependent lyase and $\alpha \mathrm{KG}$ dependent dioxygenase, and the SDR FlvB. Compound 167 is then loaded onto the single-module NRPS FlvI, which performs the esterification reaction to afford 165.

\section{Other converging pathways}

In addition to the biosynthetic pathways described above, fungi accomplish pathway convergence in diverse ways. Fungal THX dimer biosynthesis is one such example. As mentioned above, fungal THX biosynthesis occurs in a highly branching way (Fig. 3); however, these monomeric THXs often undergo (hetero)dimerization reactions to provide THX (hetero)dimers, and the biosynthesis of THX heterodimers can be regarded as converging pathways. The P450 NsrP performs oxidative coupling of 5-acetylblennolide $A$ (175) and blennolide $C(\mathbf{4})$ to complete neosartorin (176) biosynthesis (Fig. 20A) [12]. Similarly, AacuE, an NsrP homologue responsible for secalonic acid biosynthesis, can accept blennolides A (2) and B (3) as substrates to generate secalonic acid F (177) (Fig. 20B) [16]. It should be noted that these P450s appear to utilize several different substrates to perform both homo- and heterodimerization reactions. For

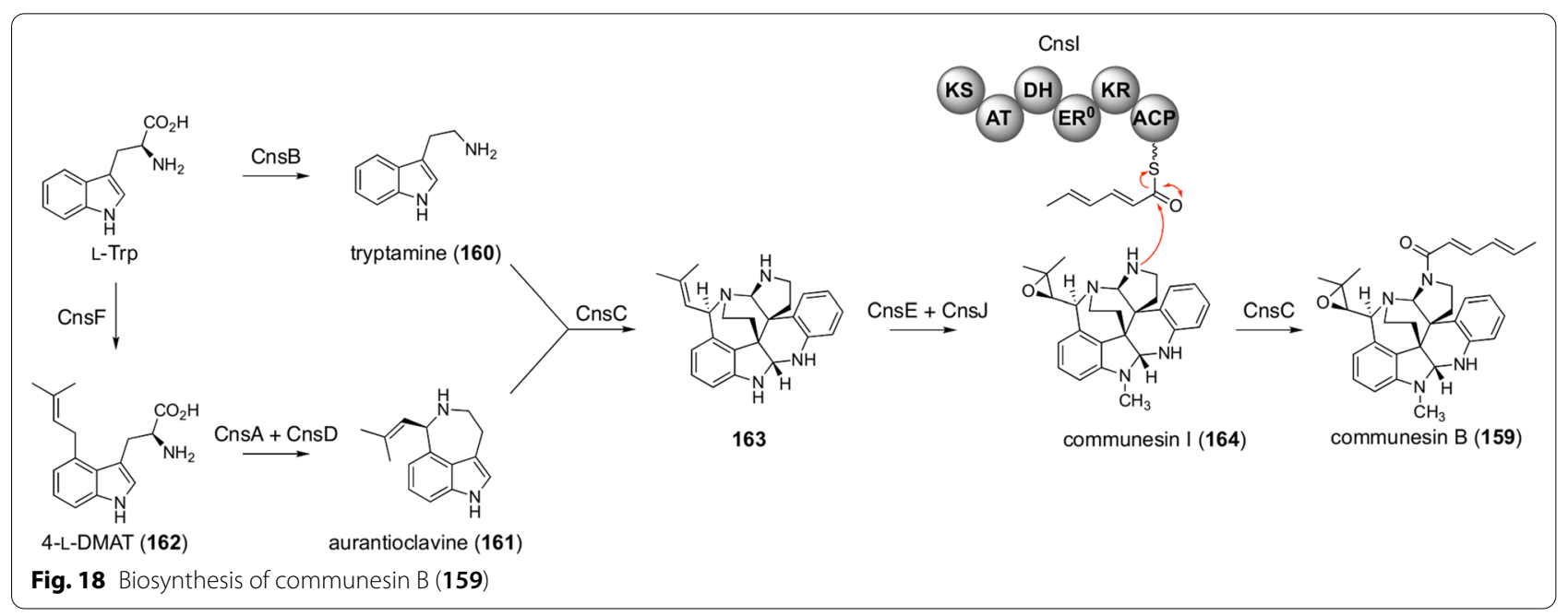




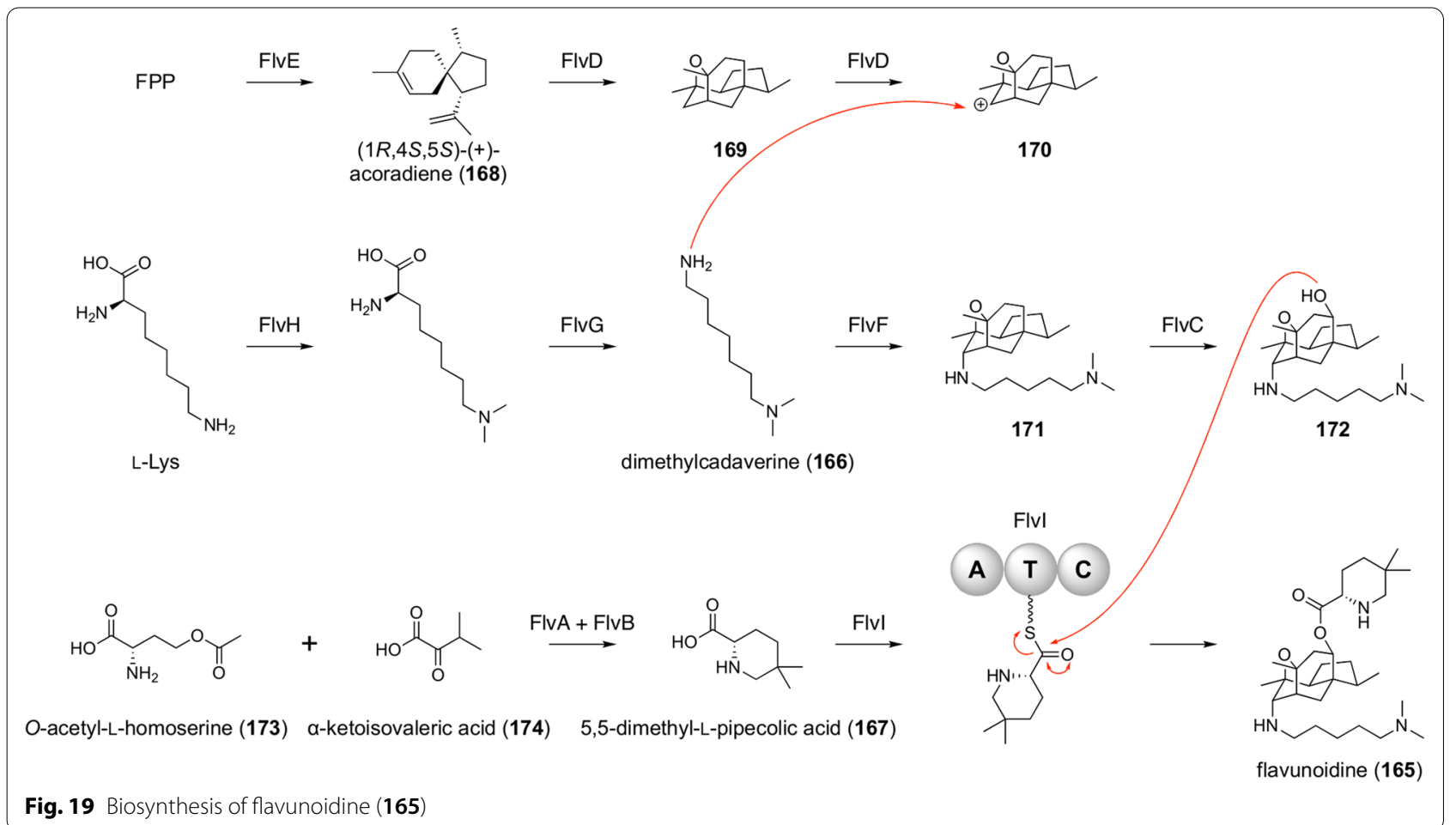

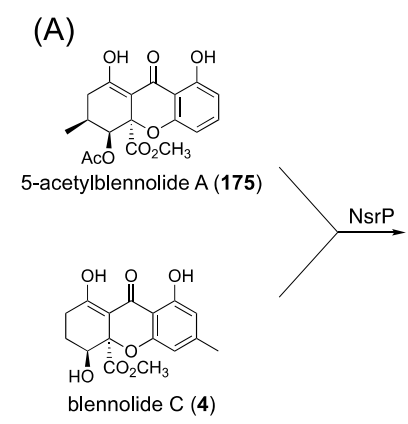

(B)

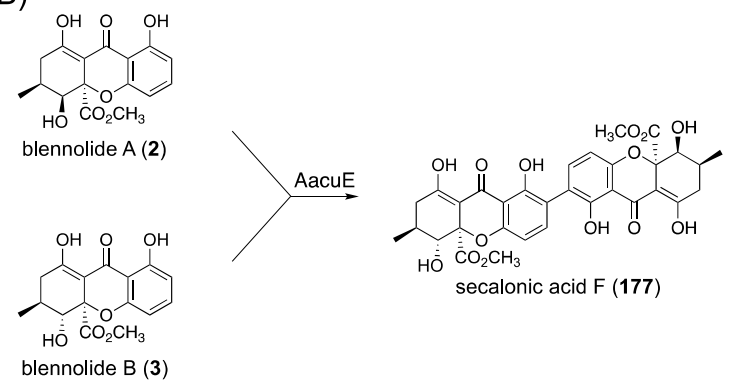

Fig. 20 P450-catalyzed oxidative coupling reactions in fungal THX heterodimer biosynthesis. Reactions catalyzed by $\mathbf{A}$ NsrP and $\mathbf{B}$ AacuE

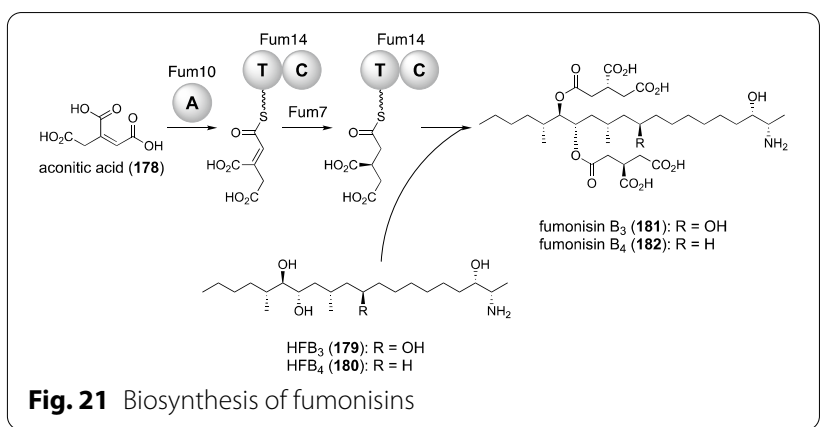

example, AacuE can synthesize secalonic acid D [16], a homodimer of 3 and a major product of the A. aculeatus secalonic acid pathway [134].

Fumonisins are mycotoxins mainly derived from Fusarium species and possess characteristic tricarballylic ester moieties [135]. The tricaballylate portion is derived from aconitic acid (178), which is activated by the standalone A domain Fum10 and subsequently loaded onto the NRPS-like enzyme Fum14 with T-C domain organization (Fig. 21) [136]. It has been proposed that the tricaballylate bound to Fum14 undergoes enoylreduction catalyzed by the iron-containing dehydrogenase/reductase Fum7 [137]. The Fum14 C domain would then utilize hydrolyzed fumonisin $B_{3}$ 
(179; $\left.\mathrm{HFB}_{3}\right)$ or hydrolyzed fumonisin $\mathrm{B}_{4}\left(\mathbf{1 8 0} ; \mathrm{HFB}_{4}\right)$, which are synthesized in a separate pathway, to perform the esterification reaction. The resultant monoacylated products would again be accepted by the $C$ domain to provide fumonisin $B_{3}(\mathbf{1 8 1})$ or fumonisin $B_{4}(\mathbf{1 8 2})$.

Maleidrides are carbocyclic molecules harboring one or two maleic anhydride groups [138], and their biosynthesis involves an enzyme-catalyzed heterodimerization reaction to synthesize the core structure. In the biosynthesis of byssochlamic acid (183), butenyl carboxymethyl maleic anhydride (184) and its decarboxylated form $\mathbf{1 8 5}$ are enzymatically hybridized (Fig. 22A) [139]; the maleic anhydride derivative $\mathbf{1 8 4}$ originates from hexenoate synthesized by a PKS and oxaloacetate. The reaction to generate 183 is catalyzed by the ketosteroid isomerase (KSI)-like proteins BfL6 and BfL10, and the product yield is significantly increased in the presence of phosphatidylethanolamine-binding proteins (PEBPs) BfL5 and BfL9. Deoxyscytalidin (186) biosynthesis occurs in a similar manner to 183, except that octanoate is used as a building block instead of hexenoate (Fig. 22A) [140]. The fusion reaction in the scytalidin pathway is performed by the KSI ScyR6 and the PEBPs ScyL1 and ScyR12. Rubratoxin A biosynthesis constructs the maleidride scaffold in a similar manner with the aid of the KSI RbtR and the PEBPs RbtM and RbtO by utilizing two carboxymethyl maleic anhydride molecules with slightly different side chains, 187 and 188, to afford prerubratoxin A1 (189) (Fig. 22B) [141].
(A)

(B)

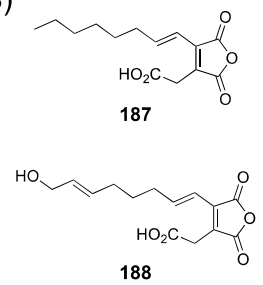

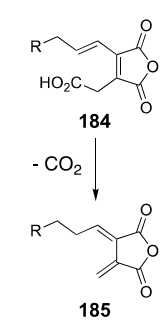
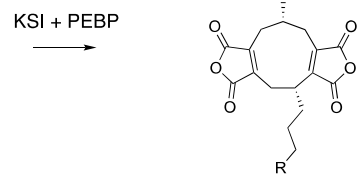

byssochlamic acid (183): $\mathrm{R}=\mathrm{H}$ deoxyscytalidin (186): $\mathrm{R}=\mathrm{C}_{2} \mathrm{H}_{5}$

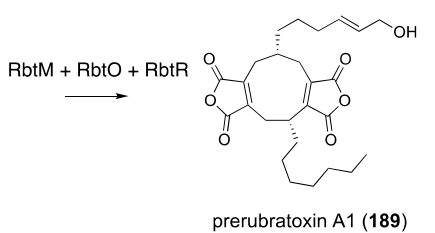

Fig. 22 Biosynthesis of maleidrides. A Biosynthesis of byssochlamic acid (183) and deoxyscytalidin (186). B Biosynthesis of prerubratoxin A1 (189)
(A)

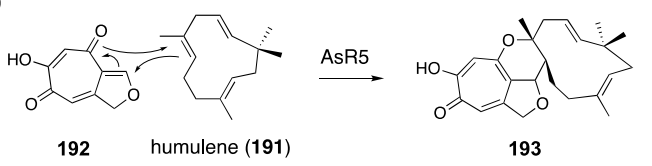

(B)

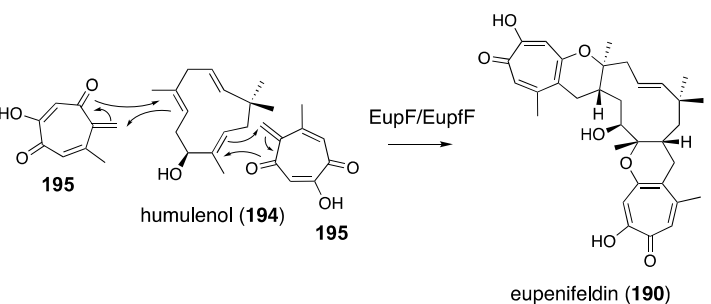

Fig. 23 Hetero $[4+2]$ cycloaddition reactions in fungal meroterpenoid biosynthesis. Reactions catalyzed by $\mathbf{A}$ AsR5 and $\mathbf{B}$ EupF/EupfF

Xenovulene A and eupenifeldin (190) are polyketidederived fungal meroterpenoids synthesized in a distinct manner from those described above. The biosynthesis of these molecules employs a class I terpene cyclase, and therefore, the resultant terpene products need to be hybridized with a polyketide molecule at a later biosynthesis stage. In the biosynthesis of xenovulene A, the sesquiterpene hydrocarbon humulene (191) and the tropolone quinomethide (192) undergo a hetero [4+2] cycloaddition reaction catalyzed by AsR5 to give 193 with the meroterpenoid scaffold (Fig. 23A) [142]. The eupenifeldin pathway also adopts a homologous enzyme EupF or EupfF, which catalyzes hetero [4+2] cycloaddition reactions at two distinct positions of the sesquiterpene alcohol humulenol (194) using two tropolone orthoquinone molecules (195) (Fig. 23B) [143, 144].

Azasperpyranone A (196) is an azaphilone family natural product biosynthesized by the fusion of preasperpyranone (197) and a polyketide-derived aromatic aldehyde 198, which, unlike the other cases covered in this review, are generated by two separate gene clusters (Fig. 24) [145]. However, a gene deletion experiment indicated that ATEG_03636 is responsible for this heterodimerization reaction. ATEG_03636 does not exhibit sequence

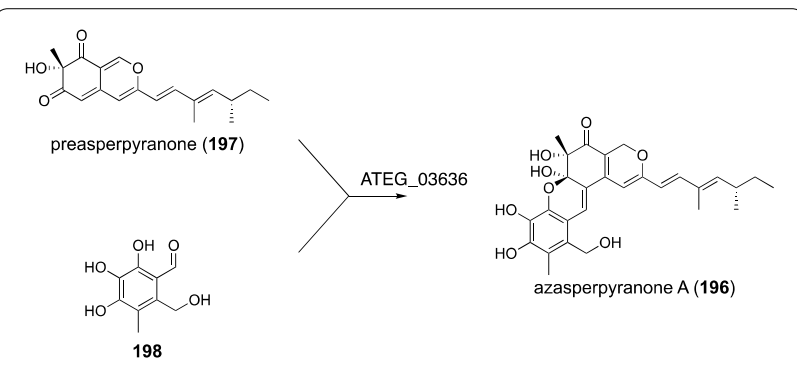

Fig. 24 Biosynthesis of azasperpyranone A (196) 
similarity to any characterized proteins, and the detailed mechanism by which the enzyme performs the hybridization reaction has yet to be elucidated.

\section{Concluding remarks}

In this review, we summarize several representative examples of branching and converging pathways found in fungal natural product biosynthesis. Core synth(et)ases, such as PKSs, NRPSs, and terpene cyclases, undoubtfully contribute to the structural diversity of natural products by creating a large number of branching pathways, which is achieved by the diverse programming rules adopted by core synth(et)ases. However, pathway branching and converging at mid- and late-stage biosynthesis, which are performed by a variety of tailoring enzymes, are other major factors that generate the natural product diversity and complexity. It should be noted that only slight genetic changes can sometimes cause a pathway divergence; for example, the divergence of paraherquonin and acetoxydehydroaustin pathways in Penicillium brasilianum stems from the change of a few amino acid residues in the key dioxygenases [79]. The presence of diverse branching and converging pathways might be attributed to nature's evolutionary efforts to synthesize diverse molecules from a relatively small number of available starting materials. Given the recent rapid accumulation and advances in genome editing and heterologous expression technologies [146, 147], an increasing number of branching and converging biosynthesis pathways will be identified and characterized in the near future, which could lead to the discovery of novel biosynthetic mechanisms for pathway branching or convergence. The elucidation and understanding of such biosynthetic pathways will also facilitate the construction of artificial branching and converging metabolic pathways, as exemplified by the expansion of meroditerpenoid pyrone pathways [92], the evolution of the acyltransferase LovD into a simvastatin synthase [148], and the side-chain engineering of pneumocandins [149]. Future studies might discover more branching and converging pathways and rationally engineer biosynthesis to further expand natural product diversity and provide useful molecules in an efficient and selective manner.

\footnotetext{
Abbreviations

4-HPPA: 4-Hydroxyphenylpyruvic acid; aKG: a-Ketoglutarate; A: Adenylation; C: Condensation; CoA: Coenzyme A; $C_{T}$ : Terminal condensation-like; DMAPP: Dimethylallyl pyrophosphate; DMAT: Dimethylallyltryptophan; DMATS: Dimethylallyltryptophan synthase; DMOA: 3,5-Dimethylorsellinic acid; DON: Deoxynivalenol; EPT: 12,13-Epoxytrichothec-9-ene; ER: Enoylreductase; FMO: Flavin-dependent monooxygenase; FPP: Farnesyl pyrophosphate; KSI: Ketosteroid isomerase; NIV: Nivalenol; NRPS: Nonribosomal peptide synthetase; PEBP: Phosphatidylethanolamine-binding proteins; PKS: Polyketide synthase; R: Reductase; SDR: Short-chain dehydrogenase/reductase; SQTKS: Squalestatin tetraketide synthase; T: Thiolation; TAL: Triacetic acid lactone; THX: Tetrahydroxanthone.
}

Acknowledgements

Not applicable.

Authors' contributions

All authors read and approved the manuscript.

Funding

This work was in part supported by the Early Career Scheme grant from the Research Grants Council (RGC) of Hong Kong (Project No. 21300219 to Y.M.).

\section{Declarations}

Ethics approval and consent to participate

Not applicable.

Consent for publication

Not applicable.

\section{Competing interests}

The authors declare no competing financial interest.

\section{Availability of data and materials}

Not applicable.

\section{Author details}

'Department of Chemistry, City University of Hong Kong, Tat Chee Avenue, Kowloon, Hong Kong SAR, China. ${ }^{2}$ Key Laboratory of Chemistry in Ethnic Medicinal Resources, State Ethnic Affairs Commission and Ministry of Education and Key Laboratory of Natural Products Synthetic Biology of Ethnic Medicinal Endophytes, State Ethnic Affairs Commission, Yunnan Minzu University, Kunming 650031, China.

Received: 31 December 2021 Accepted: 19 February 2022

Published online: 07 March 2022

\section{References}

1. Fischbach MA, Walsh CT. Assembly-line enzymology for polyketide and nonribosomal peptide antibiotics: Logic, machinery, and mechanisms. Chem Rev. 2006;106:3468-96.

2. Nivina A, Yuet KP, Hsu J, Khosla C. Evolution and diversity of assemblyline polyketide synthases. Chem Rev. 2019;119:12524-47.

3. Herbst DA, Townsend CA, Maier T. The architectures of iterative type I PKS and FAS. Nat Prod Rep. 2018;35:1046-69.

4. Christianson DW. Structural and chemical biology of terpenoid cyclases. Chem Rev. 2017;117:11570-648.

5. Firn RD, Jones $\mathrm{CG}$. Natural products - a simple model to explain chemical diversity. Nat Prod Rep. 2003;20:382-91.

6. Masters K-S, Bräse S. Xanthones from fungi, lichens, and bacteria: The natural products and their synthesis. Chem Rev. 2012;112:3717-76.

7. Wezeman T, Bräse S, Masters K-S. Xanthone dimers: a compound family which is both common and privileged. Nat Prod Rep. 2015;32:6-28.

8. Sanchez JF, Entwistle R, Hung J-H, Yaegashi J, Jain S, Chiang Y-M, Wang CCC, Oakley BR. Genome-based deletion analysis reveals the prenyl xanthone biosynthesis pathway in Aspergillus nidulans. J Am Chem Soc. 2011;133:4010-7.

9. Simpson TJ. Genetic and biosynthetic studies of the fungal prenylated xanthone shamixanthone and related metabolites in Aspergillus spp. revisited. ChemBioChem. 2012;13:1680-8.

10. Schätzle MA, Husain SM, Ferlaino S, Müller M. Tautomers of anthrahydroquinones: Enzymatic reduction and implications for chrysophanol, monodictyphenone, and related xanthone biosyntheses. J Am Chem Soc. 2012;134:14742-5.

11. Neubauer L, Dopstadt J, Humpf H-U, Tudzynski P. Identification and characterization of the ergochrome gene cluster in the plant pathogenic fungus Claviceps purpurea. Fungal Biol Biotechnol. 2016;3:2.

12. Matsuda $Y$, Gotfredsen $C H$, Larsen TO. Genetic characterization of neosartorin biosynthesis provides insight into heterodimeric natural product generation. Org Lett. 2018;20:7197-200. 
13. Szwalbe AJ, Williams K, Song Z, de Mattos-Shipley K, Jason L, Bailey AM, Willis $C L$, Cox RJ, Simpson TJ. Characterisation of the biosynthetic pathway to agnestins $A$ and $B$ reveals the reductive route to chrysophanol in fungi. Chem Sci. 2019;10:233-8.

14. Greco C, de Mattos-Shipley K, Andrew M, Mulholland NP, Vincent JL, Willis CL, Cox RJ, Simpson TJ. Structure revision of cryptosporioptides and determination of the genetic basis for dimeric xanthone biosynthesis in fungi. Chem Sci. 2019;10:2930-9.

15. Wei $X$, Matsuda $Y$. Unraveling the fungal strategy for tetrahydroxanthone biosynthesis and diversification. Org Lett. 2020;22:1919-23.

16. Wei X, Chen X, Chen L, Yan D, Wang W-G, Matsuda Y. Heterologous biosynthesis of tetrahydroxanthone dimers: Determination of key factors for selective or divergent synthesis. J Nat Prod. 2021;5:1544-9.

17. Wen Z, Karsten K, Zia-Ullah A, Ulrich F, Gennaro P, Lorenzo DB, Sándor A, Tibor K, Joachim R, Siegfried D, Barbara S. New mono- and dimeric members of the secalonic acid family: Blennolides $\mathrm{A}-\mathrm{G}$ isolated from the fungus Blennoria sp. Chem Eur J. 2008;14:4913-23.

18. Steyn PS. The isolation, structure and absolute configuration of secalonic acid D, the toxic metabolite of Penicillium oxalicum. Tetrahedron. 1970;26:51-7.

19. Proksa B, Uhrín D, Liptaj T, Šturdíková M. Neosartorin, an ergochrome biosynthesized by Neosartorya fischeri. Phytochemistry. 1998:48:1161-4

20. Ola ARB, Debbab A, Aly AH, Mandi A, Zerfass I, Hamacher A, Kassack MU, Brötz-Oesterhelt H, Kurtan T, Proksch P. Absolute configuration and antibiotic activity of neosartorin from the endophytic fungus Aspergillus fumigatiaffinis. Tetrahedron Lett. 2014;55:1020-3.

21. Qi F, Zhang W, Xue Y, Geng C, Huang X, Sun J, Lu X. Bienzyme-catalytic and dioxygenation-mediated anthraquinone ring opening. J Am Chem Soc. 2021;143:16326-31.

22. Yang J, Mori T, Wei X, Matsuda Y, Abe I. Structural basis for isomerization reactions in fungal tetrahydroxanthone biosynthesis and diversification. Angew Chem Int Ed. 2021;60:19458-65.

23. Wagenaar MM, Clardy J. Dicerandrols, new antibiotic and cytotoxic dimers produced by the fungus Phomopsis longicolla isolated from an endangered mint. J Nat Prod. 2001;64:1006-9.

24. Ganapathy D, Reiner JR, Valdomir G, Senthilkumar S, Tietze LF. Enantioselective total synthesis and structure confirmation of the natural dimeric tetrahydroxanthenone dicerandrol C. Chem Eur J. 2017;23:2299-302.

25. Wallwey C, Li S-M. Ergot alkaloids: structure diversity, biosynthetic gene clusters and functional proof of biosynthetic genes. Nat Prod Rep. 2011:28:496-510.

26. Jakubczyk D, Cheng JZ, O'Connor SE. Biosynthesis of the ergot alkaloids. Nat Prod Rep. 2014;31:1328-38.

27. Coyle CM, Cheng JZ, O'Connor SE, Panaccione DG. An old yellow enzyme gene controls the branch point between Aspergillus fumigatus and Claviceps purpurea ergot alkaloid pathways. Appl Environ Microbiol. 2010;76:3898-903.

28. Cheng JZ, Coyle CM, Panaccione DG, O'Connor SE. Controlling a structural branch point in ergot alkaloid biosynthesis. J Am Chem Soc. 2010:132:12835-7.

29. Matuschek M, Wallwey C, Xie X, Li S-M. New insights into ergot alkaloid biosynthesis in Claviceps purpurea: An agroclavine synthase EasG catalyses, via a non-enzymatic adduct with reduced glutathione, the conversion of chanoclavine-l aldehyde to agroclavine. Org Biomol Chem. 2011;9:4328-35.

30. Cheng JZ, Coyle CM, Panaccione DG, O'Connor SE. A role for old yellow enzyme in ergot alkaloid biosynthesis. J Am Chem Soc. 2010;132:1776-7.

31. Jakubczyk D, Caputi L, Hatsch A, Nielsen CAF, Diefenbacher M, Klein J, Molt A, Schröder H, Cheng JZ, Naesby M, O'Connor SE. Discovery and reconstitution of the cycloclavine biosynthetic pathwayenzymatic formation of a cyclopropyl group. Angew Chem Int Ed. 2015:54:5117-21.

32. Matuschek M, Wallwey C, Wollinsky B, Xie X, Li S-M. In vitro conversion of chanoclavine-l aldehyde to the stereoisomers festuclavine and pyroclavine controlled by the second reduction step. RSC Adv. 2012;2:3662-9.

33. Correia T, Grammel N, Ortel I, Keller U, Tudzynski P. Molecular cloning and analysis of the ergopeptine assembly system in the ergot fungus Claviceps purpurea. Chem Biol. 2003;10:1281-92.
34. Ortel I, Keller U. Combinatorial assembly of simple and complex D-lysergic acid alkaloid peptide classes in the ergot fungus Claviceps purpurea. J Biol Chem. 2009;284:6650-60.

35. Lorenz N, Wilson EV, Machado C, Schardl CL, Tudzynski P. Comparison of ergot alkaloid biosynthesis gene clusters in Claviceps species indicates loss of late pathway steps in evolution of C. fusiformis. Appl Environ Microbiol. 2007;73:7185-91.

36. Havemann J, Vogel D, Loll B, Keller U. Cyclolization of D-lysergic acid alkaloid peptides. Chem Biol. 2014:21:146-55.

37. Haarmann T, Machado C, Lübbe Y, Correia T, Schardl CL, Panaccione DG, Tudzynski P. The ergot alkaloid gene cluster in Claviceps purpurea: Extension of the cluster sequence and intra species evolution. Phytochemistry. 2005:66:1312-20.

38. Schardl CL, Young CA, Hesse U, Amyotte SG, Andreeva K, Calie PJ, Fleetwood DJ, Haws DC, Moore N, Oeser B, Panaccione DG, Schweri KK, Voisey CR, Farman ML, Jaromczyk JW, Roe BA, O'Sullivan DM, Scott B, Tudzynski P, An Z, Arnaoudova EG, Bullock CT, Charlton ND, Chen L, Cox M, Dinkins RD, Florea S, Glenn AE, Gordon A, Güldener U, Harris DR, Hollin W, Jaromczyk J, Johnson RD, Khan AK, Leistner E, Leuchtmann A, Li C, Liu J, Liu M, Mace W, Machado C, Nagabhyru P, Pan J, Schmid J, Sugawara K, Steiner U, Takach JE, Tanaka E, Webb JS, Wilson EV, Wiseman JL, Yoshida R, Zeng Z. Plant-symbiotic fungi as chemical engineers: multi-genome analysis of the clavicipitaceae reveals dynamics of alkaloid loci. PLoS Genet. 2013;9:e1003323.

39. Grove JF. Non-macrocyclic trichothecenes. Nat Prod Rep. 1988;5:187-209.

40. Grove JF. Macrocyclic trichothecenes. Nat Prod Rep. 1993;10:429-48.

41. Hohn TM, Vanmiddlesworth F. Purification and characterization of the sesquiterpene cyclase trichodiene synthetase from Fusarium sporotrichioides. Arch Biochem Biophys. 1986;251:756-61.

42. Hohn TM, Beremand PD. Isolation and nucleotide sequence of a sesquiterpene cyclase gene from the trichothecene-producing fungus Fusarium sporotrichioides. Gene. 1989;79:131-8.

43. Tokai T, Koshino H, Takahashi-Ando N, Sato M, Fujimura M, Kimura M. Fusarium Tri4 encodes a key multifunctional cytochrome P450 monooxygenase for four consecutive oxygenation steps in trichothecene biosynthesis. Biochem Biophys Res Commun. 2007:353:412-7.

44. Trapp SC, Hohn TM, McCormick S, Jarvis BB. Characterization of the gene cluster for biosynthesis of macrocyclic trichothecenes in Myrothecium roridum. Mol Gen Genet. 1998;257:421-32.

45. Garvey GS, McCormick SP, Rayment I. Structural and Functional Characterization of the TRI101 Trichothecene 3-O-Acetyltransferase from Fusarium sporotrichioides and Fusarium graminearum: KINETIC INSIGHTS TO COMBATING FUSARIUM HEAD BLIGHT. J Biol Chem. 2008;283:1660-9.

46. Alexander NJ, Hohn TM, McCormick SP. The TR/11 gene of Fusarium sporotrichioides encodes a cytochrome P-450 monooxygenase required for C-15 hydroxylation in trichothecene biosynthesis. Appl Environ Microbiol. 1998:64:221-5.

47. McCormick SP, Hohn TM, Desjardins AE. Isolation and characterization of Tri3, a gene encoding 15-O-acetyltransferase from Fusarium sporotrichioides. Appl Environ Microbiol. 1996;62:353-9.

48. Garvey GS, McCormick SP, Alexander NJ, Rayment I. Structural and functional characterization of TR/3 trichothecene 15-O-acetyltransferase from Fusarium sporotrichioides. Protein Sci. 2009;18:747-61.

49. Brown DW, McCormick SP, Alexander NJ, Proctor RH, Desjardins AE. Inactivation of a cytochrome P-450 is a determinant of trichothecene diversity in Fusarium species. Fungal Genet Biol. 2002;36:224-33.

50. Brown DW, McCormick SP, Alexander NJ, Proctor RH, Desjardins AE. A genetic and biochemical approach to study trichothecene diversity in Fusarium sporotrichioides and Fusarium graminearum. Fungal Genet Biol. 2001:32:121-33.

51. Meek IB, Peplow AW, Charles A, Phillips TD, Beremand MN. Tri1 encodes the cytochrome P450 monooxygenase for C-8 hydroxylation during trichothecene biosynthesis in Fusarium sporotrichioides and resides upstream of another new Tri gene. Appl Environ Microbiol. 2003:69:1607-13.

52. Peplow AW, Meek IB, Wiles MC, Phillips TD, Beremand MN. Tri16 is required for esterification of position C-8 during trichothecene mycotoxin production by Fusarium sporotrichioides. Appl Environ Microbiol. 2003:69:5935-40 
53. McCormick SP, Alexander NJ. Fusarium Tri8 encodes a trichothecene C-3 esterase. Appl Environ Microbiol. 2002;68:2959-64.

54. Ichinoe M, Kurata H, Sugiura Y, Ueno Y. Chemotaxonomy of Gibberella zeae with special reference to production of trichothecenes and zearalenone. Appl Environ Microbiol. 1983:46:1364-9.

55. McCormick SP, Harris $\sqcup$, Alexander NJ, Ouellet T, Saparno A, Allard S, Desjardins AE. Tri 1 in Fusarium graminearum encodes a P450 oxygenase. Appl Environ Microbiol. 2004;70:2044-51.

56. Lee T, Han Y-K, Kim K-H, Yun S-H, Lee Y-W. Tri13 and Tri7 determine deoxynivalenol- and nivalenol-producing chemotypes of Gibberella zeae. Appl Environ Microbiol. 2002;68:2148-54.

57. Cardoza RE, Malmierca MG, Hermosa MR, Alexander NJ, McCormick SP, Proctor RH, Tijerino AM, Rumbero A, Monte E, Gutiérrez S. Identification of loci and functional characterization of trichothecene biosynthesis genes in filamentous fungi of the genus Trichoderma. Appl Environ Microbiol. 2011;77:4867-77.

58. Cardoza RE, McCormick SP, Lindo L, Kim H-S, Olivera ER, Nelson DR, Proctor RH, Gutiérrez S. A cytochrome P450 monooxygenase gene required for biosynthesis of the trichothecene toxin harzianum $A$ in Trichoderma. Appl Microbiol Biotechnol. 2019;103:8087-103.

59. Gyimesi J, Melera A. On the structure of crotocin an antifungal antibiotic. Tetrahedron Lett. 1967;8:1665-73.

60. Kupchan SM, Jarvis BB, Dailey RG, Bright W, Bryan RF, Shizuri Y. Tumor inhibitors. 119. Baccharin, a novel potent antileukemic trichothecene triepoxide from Baccharis megapotamica. J Am Chem Soc. 1976;98:7092-3.

61. Breitenstein W, Tamm C. ${ }^{13} \mathrm{C}-\mathrm{NMR}$.-Spectroscopy of the trichothecane derivatives verrucarol, verrucarins $A$ and $B$ and roridins $A, D$ and $H$ verrucarins and roridins, 33rd Communication [1]. Helv Chim Acta. 1975;58:1172-80.

62. Eppley RM, Mazzola EP, Highet RJ, Bailey WJ. Structure of satratoxin H, a metabolite of Stachybotrys atra. Application of proton and carbon-13 nuclear magnetic resonance. J Org Chem. 1977:42:240-3.

63. Zeng H, Yin G, Wei Q, Li D, Wang Y, Hu Y, Hu C, Zou Y. Unprecedented [5.5.5.6]dioxafenestrane ring construction in fungal insecticidal sesquiterpene biosynthesis. Angew Chem Int Ed. 2019;58:6569-73.

64. Wei Q, Zeng H-C, Zou Y. Divergent biosynthesis of fungal dioxafenestrane sesquiterpenes by the cooperation of distinctive Baeyer-Villiger monooxygenases and a-ketoglutarate-dependent dioxygenases. ACS Catal. 2021;11:948-57.

65. Von Daehne W, Godtfredsen WO, Rasmussen PR. Structure-activity relationships in fusidic acid-type antibiotics. Adv Appl Microbiol. 1979;25:95-146.

66. Fernandes P. Fusidic acid: A bacterial elongation factor inhibitor for the oral treatment of acute and chronic staphylococcal infections. Cold Spring Harb Perspect Med. 2016;6:a025437.

67. Mitsuguchi H, Seshime Y, Fujii I, Shibuya M, Ebizuka Y, Kushiro T. Biosynthesis of steroidal antibiotic fusidanes: Functional analysis of oxidosqualene cyclase and subsequent tailoring enzymes from Aspergillus fumigatus. J Am Chem Soc. 2009;131:6402-11.

68. Lv J-M, Hu D, Gao H, Kushiro T, Awakawa T, Chen G-D, Wang C-X, Abe I, Yao X-S. Biosynthesis of helvolic acid and identification of an unusual C-4-demethylation process distinct from sterol biosynthesis. Nat Commun. 2017;8:1644.

69. Cao Z, Li S, LV J, Gao H, Chen G, Awakawa T, Abe I, Yao X, Hu D. Biosynthesis of clinically used antibiotic fusidic acid and identification of two short-chain dehydrogenase/reductases with converse stereoselectivity. Acta Pharm Sin B. 2019;9:433-42.

70. Cao Z-Q, Lv J-M, Liu Q, Qin S-Y, Chen G-D, Dai P, Zhong Y, Gao H, Yao X-S, $\mathrm{Hu}$ D. Biosynthetic study of cephalosporin $\mathrm{P}_{1}$ reveals a multifunctional P450 enzyme and a site-selective acetyltransferase. ACS Chem Biol. 2020;15:44-51.

71. Geris R, Simpson TJ. Meroterpenoids produced by fungi. Nat Prod Rep. 2009;26:1063-94.

72. Matsuda Y, Abe I. Biosynthesis of fungal meroterpenoids. Nat Prod Rep. 2016:33:26-53.

73. Jiang $M, W u Z, L i u L, C h e n S$. The chemistry and biology of fungal meroterpenoids (2009-2019). Org Biomol Chem. 2021;19:1644-704

74. Matsuda Y, Awakawa T, Itoh T, Wakimoto T, Kushiro T, Fujii I, Ebizuka Y, Abe I. Terretonin biosynthesis requires methylation as essential step for cyclization. ChemBioChem. 2012;13:1738-41.
75. Matsuda Y, Awakawa T, Abe I. Reconstituted biosynthesis of fungal meroterpenoid andrastin A. Tetrahedron. 2013;69:8199-204.

76. Matsuda Y, Bai T, Phippen CBW, Nødvig CS, Kjærbølling I, Vesth TC, Andersen MR, Mortensen UH, Gotfredsen CH, Abe I, Larsen TO. Novofumigatonin biosynthesis involves a non-heme iron-dependent endoperoxide isomerase for orthoester formation. Nat Commun. 2018;9:2587.

77. Mitsuhashi T, Barra L, Powers Z, Kojasoy V, Cheng A, Yang F, Taniguchi Y, Kikuchi T, Fujita M, Tantillo DJ, Porco JA Jr, Abe I. Exploiting the potential of meroterpenoid cyclases to expand the chemical space of fungal meroterpenoids. Angew Chem Int Ed. 2020;59:23772-81.

78. Matsuda Y, Awakawa T, Wakimoto T, Abe I. Spiro-ring formation is catalyzed by a multifunctional dioxygenase in austinol biosynthesis. J Am Chem Soc. 2013;135:10962-5.

79. Matsuda Y, Iwabuchi T, Fujimoto T, Awakawa T, Nakashima Y, Mori T, Zhang H, Hayashi F, Abe I. Discovery of key dioxygenases that diverged the paraherquonin and acetoxydehydroaustin pathways in Penicillium brasilianum. J Am Chem Soc. 2016;138:12671-7.

80. Nakashima Y, Mori T, Nakamura H, Awakawa T, Hoshino S, Senda M, Senda T, Abe I. Structure function and engineering of multifunctional non-heme iron dependent oxygenases in fungal meroterpenoid biosynthesis. Nat Commun. 2018;9:104.

81. Matsuda Y, Wakimoto T, Mori T, Awakawa T, Abe I. Complete biosynthetic pathway of anditomin: Nature's sophisticated synthetic route to a complex fungal meroterpenoid. J Am Chem Soc. 2014;136:15326-36.

82. Bai T, Matsuda Y, Tao H, Mori T, Zhang Y, Abe I. Structural diversification of andiconin-derived natural products by a-ketoglutarate-dependent dioxygenases. Org Lett. 2020;22:4311-5.

83. Araki Y, Awakawa T, Matsuzaki M, Cho R, Matsuda Y, Hoshino S, Shinohara Y, Yamamoto M, Kido Y, Inaoka DK, Nagamune K, Ito K, Abe I, Kita K. Complete biosynthetic pathways of ascofuranone and ascochlorin in Acremonium egyptiacum. Proc Natl Acad Sci USA. 2019;116:8269-74.

84. Li C, Matsuda Y, Gao H, Hu D, Yao XS, Abe I. Biosynthesis of LL-Z1272ß: Discovery of a new member of NRPS-like enzymes for aryl-aldehyde formation. ChemBioChem. 2016;17:904-7.

85. Lin T-S, Chiang Y-M, Wang CCC. Biosynthetic pathway of the reduced polyketide product citreoviridin in Aspergillus terreus var. aureus revealed by heterologous expression in Aspergillus nidulans. Org Lett. 2016;18:1366-9.

86. Mao X-M, Zhan Z-J, Grayson MN, Tang M-C, Xu W, Li Y-Q, Yin W-B, Lin $\mathrm{H}-\mathrm{C}$, Chooi Y-H, Houk KN, Tang Y. Efficient biosynthesis of fungal polyketides containing the dioxabicyclo-octane ring system. J Am Chem Soc. 2015;137:11904-7.

87. Wang W-G, Du L-Q, Sheng S-L, Li A, Li Y-P, Cheng G-G, Li G-P, Sun G, Hu Q, Matsuda Y. Genome mining for fungal polyketide-diterpenoid hybrids: Discovery of key terpene cyclases and multifunctional P450s for structural diversification. Org Chem Front. 2019;6:571-8.

88. Kanokmedhakul K, Kanokmedhakul S, Suwannatrai R, Soytong K, Prabpai S, Kongsaeree P. Bioactive meroterpenoids and alkaloids from the fungus Eurotium chevalieri. Tetrahedron. 2011;67:5461-8.

89. Bai T, Quan Z, Zhai R, Awakawa T, Matsuda Y, Abe I. Elucidation and heterologous reconstitution of chrodrimanin B biosynthesis. Org Lett. 2018;8:7504-8.

90. Li X, Awakawa T, Mori T, Ling M, Hu D, Wu B, Abe I. Heterodimeric nonheme iron enzymes in fungal meroterpenoid biosynthesis. J Am Chem Soc. 2021;143:21425-32.

91. Kato H, Tsunematsu Y, Yamamoto T, Namiki T, Kishimoto S, Noguchi H, Watanabe K. New natural products isolated from Metarhizium robertsii ARSEF 23 by chemical screening and identification of the gene cluster through engineered biosynthesis in Aspergillus nidulans A1145. J Antibiot. 2016;69:561-6.

92. Tsukada K, Shinki S, Kaneko A, Murakami K, Irie K, Murai M, Miyoshi H, Dan S, Kawaji K, Hayashi H, Kodama EN, Hori A, Salim E, Kuraishi T, Hirata $\mathrm{N}$, Kanda Y, Asai T. Synthetic biology based construction of biological activity-related library of fungal decalin-containing diterpenoid pyrones. Nat Commun. 2020;11:1830.

93. Wei X, Matsuyama T, Sato H, Yan D, Chan PM, Miyamoto K, Uchiyama M, Matsuda Y. Molecular and computational bases for spirofuranone formation in setosusin biosynthesis. J Am Chem Soc. 2021;143:17708-15.

94. Macías FA, Varela RM, Simonet AM, Cutler HG, Cutler SJ, Dugan FM, Hill RA. Novel bioactive breviane spiroditerpenoids from Penicillium brevicompactum Dierckx. J Org Chem. 2000;65:9039-46. 
95. Reddy P, Guthridge K, Vassiliadis S, Hemsworth J, Hettiarachchige I, Spangenberg G, Rochfort S. Tremorgenic mycotoxins: structure diversity and biological activity. Toxins. 2019;11:302.

96. Tang M-C, Lin H-C, Li D, Zou Y, Li J, Xu W, Cacho RA, Hillenmeyer ME, Garg NK, Tang Y. Discovery of unclustered fungal indole diterpene biosynthetic pathways through combinatorial pathway reassembly in engineered yeast. J Am Chem Soc. 2015;137:13724-7.

97. Tagami K, Liu C, Minami A, Noike M, Isaka T, Fueki S, Shichijo Y, Toshima H, Gomi K, Dairi T, Oikawa H. Reconstitution of biosynthetic machinery for indole-diterpene paxilline in Aspergillus oryzae. J Am Chem Soc. 2013;135:1260-3.

98. Saikia S, Parker E, Koulman A, Scott B. Four gene products are required for the fungal synthesis of the indole-diterpene, paspaline. FEBS Lett. 2006;580:1625-30.

99. Liu C, Tagami K, Minami A, Matsumoto T, Frisvad JC, Suzuki H, Ishikawa J, Gomi K, Oikawa H. Reconstitution of biosynthetic machinery for the synthesis of the highly elaborated indole diterpene penitrem. Angew Chem Int Ed. 2015;54:5748-52.

100. Nicholson MJ, Koulman A, Monahan BJ, Pritchard BL, Payne GA, Scott B. Identification of two aflatrem biosynthesis gene loci in Aspergillus flavus and metabolic engineering of Penicillium paxilli to elucidate their function. Appl Environ Microbiol. 2009;75:7469-81.

101. Liu C, Minami A, Noike M, Toshima H, Oikawa H, Dairi T. Regiospecificities and prenylation mode specificities of the fungal indole diterpene prenyltransferases AtmD and PaxD. Appl Environ Microbiol. 2013;79:7298-304.

102. Tagami K, Minami A, Fujii R, Liu C, Tanaka M, Gomi K, Dairi T, Oikawa H. Rapid reconstitution of biosynthetic machinery for fungal metabolites in Aspergillus oryzae: Total biosynthesis of aflatrem. ChemBioChem. 2014;15:2076-80.

103. Nicholson MJ, Eaton CJ, Stärkel C, Tapper BA, Cox MP, Scott B. Molecular cloning and functional analysis of gene clusters for the biosynthesis of indole-diterpenes in Penicillium crustosum and P. janthinellum. Toxins. 2015;7:2701-22

104. Liu C, Minami A, Dairi T, Gomi K, Scott B, Oikawa H. Biosynthesis of shearinine: diversification of a tandem prenyl moiety of fungal indole diterpenes. Org Lett. 2016;18:5026-9.

105. Young C, Felitti S, Shields K, Spangenberg G, Johnson R, Bryan G, Saikia $S$, Scott B. A complex gene cluster for indole-diterpene biosynthesis in the grass endophyte Neotyphodium lolii. Fungal Genet Biol. 2006:43:679-93.

106. Motoyama T, Hayashi T, Hirota H, Ueki M, Osada H. Terpendole E, a kinesin Eg5 inhibitor, is a key biosynthetic intermediate of indolediterpenes in the producing fungus Chaunopycnis alba. Chem Biol. 2012;19:1611-9.

107. Saikia S, Takemoto D, Tapper B, Lane G, Fraser K, Scott B. Functional analysis of an indole-diterpene gene cluster for lolitrem $B$ biosynthesis in the grass endosymbiont Epichloë festucae. FEBS Lett. 2012;586:2563-9.

108. Jiang Y, Ozaki T, Harada M, Miyasaka T, Sato H, Miyamoto K, Kanazawa J, Liu C, Maruyama J-I, Adachi M, Nakazaki A, Nishikawa T, Uchiyama M, Minami A, Oikawa H. Biosynthesis of indole diterpene lolitrems: Radical-induced cyclization of an epoxyalcohol affording a characteristic lolitremane skeleton. Angew Chem Int Ed. 2020;59:17996-8002.

109. Xie X, Watanabe K, Wojcicki WA, Wang CC, Tang Y. Biosynthesis of lovastatin analogs with a broadly specific acyltransferase. Chem Biol. 2006;13:1161-9.

110. Bonsch B, Belt V, Bartel C, Duensing N, Koziol M, Lazarus CM, Bailey AM, Simpson TJ, Cox RJ. Identification of genes encoding squalestatin S1 biosynthesis and in vitro production of new squalestatin analogues. Chem Commun. 2016;52:6777-80

111. Lebe KE, Cox RJ. Oxidative steps during the biosynthesis of squalestatin S1. Chem Sci. 2019;10:1227-31.

112. Mattern DJ, Valiante V, Horn F, Petzke L, Brakhage AA. Rewiring of the austinoid biosynthetic pathway in filamentous fungi. ACS Chem Biol. 2017;12:2927-33.

113. Lin H-C, Chooi Y-H, Dhingra S, Xu W, Calvo AM, Tang Y. The fumagillin biosynthetic gene cluster in Aspergillus fumigatus encodes a cryptic terpene cyclase involved in the formation of $\beta$-trans-bergamotene. J Am Chem Soc. 2013;135:4616-9.
114. Tao H, Mori T, Wei X, Matsuda Y, Abe I. One polyketide synthase, two distinct products: Trans-acting enzyme-controlled product divergence in calbistrin biosynthesis. Angew Chem Int Ed. 2021;60:8851-8.

115. Wang W-G, Wang H, Du L-Q, Li M, Chen L, Yu J, Cheng G-G, Zhan M-T, Hu Q-F, Zhang L, Yao M, Matsuda Y. Molecular basis for the biosynthesis of an unusual chain-fused polyketide, gregatin A. J Am Chem Soc. 2020:142:8464-72.

116. Walsh CT, O'Brien RV, Khosla C. Nonproteinogenic amino acid building blocks for nonribosomal peptide and hybrid polyketide scaffolds. Angew Chem Int Ed. 2013;52:7098-124.

117. Schwartz RE, Sesin DF, Joshua H, Wilson KE, Kempf AJ, Goklen KA, Kuehner D, Gailliot P, Gleason C, White R, Inamine E, Bills G, Salmon P, Zitano L. Pneumocandins from Zalerion arboricola. I. Discovery and isolation. J Antibiot. 1992;45:1853-66.

118. Chen L, Yue Q, Zhang X, Xiang M, Wang C, Li S, Che Y, Ortiz-López FJ, Bills GF, Liu X, An Z. Genomics-driven discovery of the pneumocandin biosynthetic gene cluster in the fungus Glarea lozoyensis. BMC Genomics. 2013:14:339.

119. Li Y, Chen L, Yue Q, Liu X, An Z, Bills GF. Genetic manipulation of the pneumocandin biosynthetic pathway for generation of analogues and evaluation of their antifungal activity. ACS Chem Biol. 2015;10:1702-10.

120. Houwaart S, Youssar L, Hüttel W. Pneumocandin biosynthesis: Involvement of a trans-selective proline hydroxylase. ChemBioChem. 2014:15:2365-9.

121. Cacho RA, Jiang W, Chooi Y-H, Walsh CT, Tang Y. Identification and characterization of the echinocandin B biosynthetic gene cluster from Emericella rugulosa NRRL 11440. J Am Chem Soc. 2012;134:16781-90.

122. Jiang W, Cacho RA, Chiou G, Garg NK, Tang Y, Walsh CT. EcdGHK are three tailoring iron oxygenases for amino acid building blocks of the echinocandin scaffold. J Am Chem Soc. 2013;135:4457-66.

123. Renata H, Shimizu E, Zwick CR. Regiodivergent biocatalytic hydroxylation of L-glutamine facilitated by characterization of non-heme dioxygenases from non-ribosomal peptide biosyntheses. Tetrahedron. 2021;90:132190

124. Wang G, Liu Z, Lin R, Li E, Mao Z, Ling J, Yang Y, Yin W-B, Xie B. Biosynthesis of antibiotic leucinostatins in bio-control fungus Purpureocillium lilacinum and their inhibition on Phytophthora revealed by genome mining. PLoS Path. 2016:12:e1005685.

125. Sato M, Yagishita F, Mino T, Uchiyama N, Patel A, Chooi Y-H, Goda Y, Xu W, Noguchi H, Yamamoto T, Hotta K, Houk KN, Tang Y, Watanabe K. Involvement of lipocalin-like CghA in decalin-forming stereoselective intramolecular [4+2] cycloaddition. ChemBioChem. 2015:16:2294-8.

126. Sato M, Dander JE, Sato C, Hung Y-S, Gao S-S, Tang M-C, Hang L, Winter JM, Garg NK, Watanabe K, Tang Y. Collaborative biosynthesis of maleimide- and succinimide-containing natural products by fungal polyketide megasynthases. J Am Chem Soc. 2017;139:5317-20.

127. Numata A, Takahashi C, Ito Y, Takada T, Kawai K, Usami Y, Matsumura E, Imachi M, Ito T, Hasegawa T. Communesins, cytotoxic metabolites of a fungus isolated from a marine alga. Tetrahedron Lett. 1993;34:2355-8.

128. Jadulco R, Edrada RA, Ebel R, Berg A, Schaumann K, Wray V, Steube K, Proksch P. New communesin derivatives from the fungus Penicillium sp derived from the mediterranean sponge Axinella verrucosa. J Nat Prod. 2004:67:78-81.

129. Hayashi H, Matsumoto H, Akiyama K. New insecticidal compounds, communesins $C, D$ and $E$, from Penicillium expansum Link MK-57. Biosci Biotechnol Biochem. 2004;68:753-6.

130. Dalsgaard PW, Blunt JW, Munro MHG, Frisvad JC, Christophersen C. Communesins $\mathrm{G}$ and $\mathrm{H}$, new alkaloids from the psychrotolerant fungus Penicillium rivulum. J Nat Prod. 2005;68:258-61.

131. Lin H-C, Chiou G, Chooi Y-H, McMahon TC, Xu W, Garg NK, Tang Y. Elucidation of the concise biosynthetic pathway of the communesin indole alkaloids. Angew Chem Int Ed. 2015;54:3004-7.

132. Lin H-C, McMahon TC, Patel A, Corsello M, Simon A, Xu W, Zhao M, Houk KN, Garg NK, Tang Y. P450-mediated coupling of indole fragments to forge communesin and unnatural isomers. J Am Chem Soc. 2016:138:4002-5.

133. Yee DA, Kakule TB, Cheng W, Chen M, Chong CTY, Hai Y, Hang LF, Hung Y-S, Liu N, Ohashi M, Okorafor IC, Song Y, Tang M, Zhang Z, Tang Y. Genome mining of alkaloidal terpenoids from a hybrid terpene and nonribosomal peptide biosynthetic pathway. J Am Chem Soc. 2020;142:710-4. 
134. Andersen R, Buechi G, Kobbe B, Demain AL. Secalonic acids D and F are toxic metabolites of Aspergillus aculeatus. J Org Chem. 1977;42:352-3.

135. Rheeder JP, Marasas WFO, Vismer HF. Production of fumonisin analogs by Fusarium species. Appl Environ Microbiol. 2002;68:2101-5.

136. Zaleta-Rivera K, Xu C, Yu F, Butchko RAE, Proctor RH, Hidalgo-Lara ME, Raza A, Dussault PH, Du L. A bidomain nonribosomal peptide synthetase encoded by FUM14 catalyzes the formation of tricarballylic esters in the biosynthesis of fumonisins. Biochemistry. 2006;45:2561-9.

137. LiY, Lou L, Cerny RL, Butchko RAE, Proctor RH, Shen Y, Du L. Tricarballylic ester formation during biosynthesis of fumonisin mycotoxins in Fusarium verticillioides. Mycology. 2013;4:179-86.

138. Szwalbe AJ, Williams K, O'Flynn DE, Bailey AM, Mulholland NP, Vincent $J$ L, Willis CL, Cox RJ, Simpson TJ. Novel nonadride, heptadride and maleic acid metabolites from the byssochlamic acid producer Byssochlamys fulva IMI 40021 - an insight into the biosynthesis of maleidrides. Chem Commun. 2015;51:17088-91.

139. Williams K, Szwalbe AJ, Mulholland NP, Vincent JL, Bailey AM, Willis CL, Simpson TJ, Cox RJ. Heterologous production of fungal maleidrides reveals the cryptic cyclization involved in their biosynthesis. Angew Chem Int Ed. 2016:55:6784-8.

140. de Mattos-Shipley KMJ, Spencer CE, Greco C, Heard DM, O'Flynn DE, Dao TT, Song Z, Mulholland NP, Vincent IL, Simpson TJ, Cox RJ, Bailey AM, Willis $C L$. Uncovering biosynthetic relationships between antifungal nonadrides and octadrides. Chem Sci. 2020;11:11570-8.

141. Bai J, Yan D, Zhang T, Guo Y, Liu Y, Zou Y, Tang M, Liu B, Wu Q, Yu S, Tang $Y$, Hu Y. A cascade of redox reactions generates complexity in the biosynthesis of the protein phosphatase-2 inhibitor rubratoxin A. Angew Chem Int Ed. 2017;56:4782-6.

142. Schor R, Schotte C, Wibberg D, Kalinowski J, Cox RJ. Three previously unrecognised classes of biosynthetic enzymes revealed during the production of xenovulene A. Nat Commun. 2018;9:1963.

143. Zhai Y, Li Y, Zhang J, Zhang Y, Ren F, Zhang X, Liu G, Liu X, Che Y. Identification of the gene cluster for bistropolone-humulene meroterpenoid biosynthesis in Phoma sp. Fungal Genet Biol. 2019;129:7-15.

144. Chen Q, Gao J, Jamieson C, Liu J, Ohashi M, Bai J, Yan D, Liu B, Che Y, Wang Y, Houk KN, Hu Y. Enzymatic intermolecular hetero-Diels-Alder reaction in the biosynthesis of tropolonic sesquiterpenes. J Am Chem Soc. 2019;141:14052-6.

145. Huang X, Zhang W, Tang S, Wei S, Lu X. Collaborative biosynthesis of a class of bioactive azaphilones by two separate gene clusters containing four PKS/NRPSs with transcriptional crosstalk in fungi. Angew Chem Int Ed. 2020;59:4349-53.

146. Meng X, Fang Y, Ding M, Zhang Y, Jia K, Li Z, Collemare J, Liu W. Developing fungal heterologous expression platforms to explore and improve the production of natural products from fungal biodiversity. Biotechnol Adv. 2022;54:107866.

147. Schuster M, Kahmann R. CRISPR-Cas9 genome editing approaches in filamentous fungi and oomycetes. Fungal Genet Biol. 2019;130:43-53.

148. Jiménez-Osés G, Osuna S, Gao X, Sawaya MR, Gilson L, Collier SJ, Huisman GW, Yeates TO, Tang Y, Houk K. The role of distant mutations and allosteric regulation on LovD active site dynamics. Nat Chem Biol. 2014;10:431-6.

149. Chen L, Li Y, Yue Q, Loksztejn A, Yokoyama K, Felix EA, Liu X, Zhang N An Z, Bills GF. Engineering of new pneumocandin side-chain analogues from Glarea lozoyensis by mutasynthesis and evaluation of their antifungal activity. ACS Chem Biol. 2016;11:2724-33.

\section{Publisher's Note}

Springer Nature remains neutral with regard to jurisdictional claims in published maps and institutional affiliations.

Ready to submit your research? Choose BMC and benefit from:

- fast, convenient online submission

- thorough peer review by experienced researchers in your field

- rapid publication on acceptance

- support for research data, including large and complex data types

- gold Open Access which fosters wider collaboration and increased citations

- maximum visibility for your research: over $100 \mathrm{M}$ website views per year

At $\mathrm{BMC}$, research is always in progress.

Learn more biomedcentral.com/submissions 